\title{
Inequality Aversion in Income, Health, and Income-related Health
}

\author{
Jeremiah Hurley $^{\mathrm{a}}$, Emmanouil Mentzakis ${ }^{\mathrm{b}}$, Marjan Walli-Attaei ${ }^{\mathrm{c}}$ \\ ${ }^{a}$ Corresponding Author; Department of Economics and Centre for Health Economics and Policy \\ Analysis, McMaster University, 1280 Main Street West, Hamilton Ontario Canada L8S 4M4; \\ hurley@mcmaster.ca \\ ${ }^{b}$ Department of Economics, University of Southampton, University Road, Southampton SO17 1 BJ \\ ${ }^{c}$ Population Health Research Institute, Hamilton Health Sciences and McMaster University, 237 \\ Barton Street East, Hamilton Ontario Canada L8L 2 X2
}

\begin{abstract}
Based on a survey of a sample of the general public, we estimate inequality aversion across income, health, and bivariate income-health. Inequality aversion is domain specific: mean inequality aversion is greater for income than for health, but the underlying distributions of aversion attitudes differ, with a highly bi-modal distribution of inequality-aversion values for health in which nearly half the participants display very low aversion and nearly half display very high aversion. Aversion to incomerelated health inequality is greater than that to income or health alone. Consistent with previous literature, we find only weak associations between aversion attitudes and individual characteristics. The magnitude of the estimates imply potentially large gains in welfare from reducing inequality in these domains.
\end{abstract}

Keywords: Inequality aversion; income inequality; health inequality; social preferences; empirical social choice JEL Classification: C91, D31, D63, I14, I31 


\section{Introduction}

Economic, social and health inequalities present major public policy challenges in many countries. The increase in income and wealth inequality in many western nations during the last part of the twentieth century is well documented (Piketty, 2013; Blundell et al., 2018; Garbinti et al., 2018). Less well appreciated has been a rising concern about health distributions in many of these same countries. In the UK, for instance, growth in life expectancy has flattened in recent years and is falling in some population groups, while health inequalities are rising (Buck et al., 2018). Similarly, life expectancy in the US has fallen in recent years while inequalities have been increasing (Murphy et al., 2018; Chetty et al., 2016).

The optimal policy response to such inequalities depends in part on citizens' attitudes toward them. Such attitudes are normally represented in economics by an inequality-aversion parameter of the individualistic social welfare function. In the standard formulation, inequality aversion is rooted in risk aversion derived from the concavity of utility (Cowell and Schokkaert, 2001). In addition to this, many (e.g., Thurow, 1971; Alexander, 1974; Alesina and Giuliano, 2011) have posited a distinct concern regarding inequality per se. Concerns about inequalities and inequities have long figured prominently in the health sector (Williams and Cookson, 2000), but studies document other-regarding preferences and people's general concern for equity and inequality in wide-ranging economic contexts (Fehr and Schmidt, 1999; Charness and Rabin, 2002; Camerer and Fehr, 2006), and the presence of inequality aversion distinct from risk aversion (Johansson-Stenman et al., 2002; Kroll and Davidovitz, 2003; Davidovitz and Kroll, 2004; Carlsson et al., 2005). Further, while risk preferences are documented to vary across decision domains (Einav et al., 2012), evidence regarding differences in inequality aversion attitudes across domains is limited (Costa-Font and Cowell, 2019). Going back at least to Tobin (1970), however, economists and others have posited that concern for inequality is domain specific and that, for instance, aversion to health inequalities is likely larger than aversion to income inequalities, in part because many accept that some degree of income inequality is necessary to provide incentives to work hard and in part because good health is a pre-requisite for engaging in a wide range of life pursuits (Anand, 2002).

Formal estimates of inequality aversion parameters confirm that, on average, individuals are averse to inequality in both income and health, though there is considerable heterogeneity of attitudes among individuals and we are unaware of any published study that provides estimates for income and health elicited obtained using the same estimation methodology. Cropper et al. (2016) elicit inequality aversion attitudes 
for each, but do so using different methodologies that are known to generate quite different estimates. Beyond differences in elicitation methods, comparison of estimates within and across domains is complicated by differences in the ways income or health are operationalized, the role of risk, the role of egoistic versus other-regarding preferences, and related matters.

For income, estimates of an Atkinson inequality aversion parameter derived using Okun's leaky bucket approach (Okun, 1975) — which asks people how much leakage, or loss, they will tolerate when transferring income from the rich to the poorfall in the range of 0.2 to 0.3 (Amiel et al., 1999; Pirttila and Uusitalo, 2010). In contrast, those derived using the distributional approach - which asks people directly about their preferences over alternative income distributions with differing means and dispersion - fall in the range of 2 to 3 (Johansson-Stenman et al., 2002; Carlsson et al., 2005; Pirttila and Uusitalo, 2010). In the health domain, the inability to transfer health directly among people renders the leaky bucket approach infeasible, so all studies adopt a variant of the distributional approach, though there is considerable diversity regarding framing of the choice scenario and the health outcome used (e.g., life expectancy at birth, remaining years of life, quality-adjusted life-years, serious illness of defined length, health risks, proportion of full health, etc.). While all find that, on average, people are averse to health inequality, estimates of Atkinson aversion parameters encompass a wide range from less than 1.5 to over 25 (Dolan and Tsuchiya, 2011; Attema et al., 2015; Cropper et al., 2016; Robson et al., 2017). We are not aware of any studies that examine socio-economic-related health inequalities within a fully bi-variate framework that presents bi-variate distributions defined over health and income and elicits an aversion parameter for a bi-variate social-welfare function.

This study presents estimates of inequality aversion parameters amongst the general public in Ontario, Canada for each of annual income, lifetime health (life expectancy), and income-related health distributions within a consistent framework that enables their comparison. ${ }^{1}$ Following the literature, we present estimates of the median value of the inequality-aversion parameter for each, but in addition estimate

\footnotetext{
${ }^{1}$ Although strictly speaking we investigate inequality aversion in two domains - annual income and lifetime health as measured by life expectancy - plus their interaction, for simplicity in the text we refer to all three as domains and refer to the two core domains as "income" and "health." Further, while we use the same estimation approach across the domains, given the differences between income and health it is not possible to frame the scenarios identically across the domains. Our design, however, strove to make them as similar as reasonably possible to enable comparison of the estimates.
} 
mean inequality aversion using both a structural approach derived from the assumed social welfare function and a reduced-form approach that imposes no assumptions on the functional form of the social welfare function. We examine the associations between observable individual characteristics and aversion attitudes, and extend the structural approach to a latent-class setting that accommodates unobserved heterogeneity across participants. Finally, we gain insight into participants' reasoning by analyzing their written explanations for why they made the choices they did.

We find substantial aversion to inequalities in both income and health. While the mean estimate of inequality aversion is greater for income than for health, more importantly, the underlying distributions of aversion attitudes differ notably, with a highly bi-modal distribution of inequality-aversion values for health whereby nearly half of the participants exhibit low levels of aversion and nearly half exhibit high levels of aversion. Although there is substantial variability in the extent of aversion across individuals, this variation is only weakly associated with socio-economic and demographic characteristics.

\section{Experimental framework}

Our objective is to empirically estimate social inequality aversion in a general population for each income, health, and income-related health using the same distributional, stated-preference experimental design. This approach presents each participant with a pair of distributions of the outcome of concern that have been constructed such that an individual with a given level of inequality aversion would be indifferent between them under the assumed social welfare function, and asks the participant which distribution they prefer. The response reveals whether the participant's inequality aversion is greater or lower than that assumed when constructing the distributions, i.e. if the participant chooses the higher mean but more unequal distribution, their inequality aversion is less than the value assumed in constructing the distributions; if the participant chooses the lower mean but more equal distribution, their inequality aversion parameter is greater than the value assumed.

We sought to measure inequality aversion through impartial judgments free from egoistic concerns. To do so, we elicited aversion to inequality in a hypothetical society of which the participants were not, and never would be, part. Further, the scenarios were constructed so as to control for extraneous factors that could potentially bias participants' responses. To avoid having participants implicitly infer unstated differences among individuals, the scenarios stated explicitly that citizens 
of the hypothetical country were similar in all aspects except for the outcome of interest (income or health). Because attitudes toward redistribution can be quite different than to inequality per se (Norton and Ariely, 2011; Alesina and Giuliano, 2011), to avoid raising redistribution sentiments, no baseline, pre-policy distribution was presented; the scenarios presented only the distributions resulting from each policy. Scenario descriptions used simple, neutral language that avoided evoking strong emotions or associations that would influence choices for reasons other than the features of the distributions alone. To avoid any possible ordering or learning effects we used a between-subject design in which each participant was randomly assigned one choice scenario pertaining to either income, health, or income-related health distributions. ${ }^{2}$ We assume five levels of income (health) in society and equal population proportions for each level (i.e., five quintiles). The description of the choice context for the income scenarios is given below; directly analogous language was used for the health and the income-health scenarios. (See Appendix A for the full experimental survey instrument.)

Imagine a hypothetical country in which citizens are identical in all ways except one: their incomes. The government must choose between implementing one of two policies. Both policies will have an impact on citizens' incomes. Indeed, the only impact of the policies is on the level and distribution of income within the population, though each policy affects the incomes of different groups differently. These impacts will not happen instantaneously, but will occur over the next 3-5 years. The table below presents information for each policy on the resulting yearly income for individuals in the country, after taking into account all taxes and government programs. (We present the same information in a graph below the table). In this country there are five levels of income, and the number of people with each income level is identical. In the table we label the income groups Inc1-Inc5, where Inc1 refers to the group with the lowest level of income and Inc5 refers to the group with highest level of income. Everyone within each income group has the same income, but incomes differ across the five groups.

The government must choose between the two policies listed. We ask you

\footnotetext{
${ }^{2}$ Although the design - including the randomization of participants to survey versions - was based purely on between-subject variation, the survey presented participants with three scenarios, one for each domain, which allowed us to test for order effects. We found order effects, and so present analyses based solely on responses to the first scenario presented as per the between-subject design.
} 
which of the two policies you would prefer that the government implement.

There is no right or wrong answer; we are interested in your personal judgment.

The first distribution of the two presented in each pair, which we refer to as the "reference" distribution, reflected the actual distribution of the outcome in Canada: for income, the actual distribution of household disposable income in 2010 (Parliament of Canada, 2013); for health, the distribution of adjusted life expectancy (HALE) for the period 2010-2011 (Statistics Canada, 2011); and for income-related health inequality, information available regarding their joint distribution. All pairs of distributions presented to participants included this reference distribution (resulting from "Policy A" and constant across all scenarios within a domain) plus a second distribution (resulting from "Policy B") with a higher mean and greater dispersion that varied according to the underlying aversion value assumed in its construction. The choice scenario did not provide an indifference option; the choice scenario also could not be skipped.

The univariate income and health distributions were constructed assuming the standard Atkinson social welfare function (Atkinson, 1970):

$$
W=\sum_{q=1}^{Q} \frac{x_{q}^{1-\epsilon}}{1-\epsilon} \text { for } \epsilon \neq 1 \text {, and } W=\sum_{q=1}^{Q} \ln \left(x_{q}\right) \text { for } \epsilon=1,
$$

where $W$ is social welfare, $x_{q}$ represents the income (health) of quintile $q$, and $q=1,2,3,4, Q$, ranked from highest to lowest denoting the five quintiles, $\epsilon$ is the inequality aversion parameter ranging between zero and $\infty$. For $\epsilon=0$ only the mean income (health) in the society matters with no concern for inequality, corresponding to a classical utilitarian social welfare function. As $\epsilon$ increases, inequality aversion grows and the weight given to individuals ranked lower in the distribution increases relative to those ranked higher in the distribution. For $\epsilon=\infty$ all that matters is the income (health) of the worst-off individual, resulting in a Rawlsian-type social welfare function.

For each of income and health we constructed a pair of distributions associated with each of five levels of inequality aversion $(\epsilon=1.0,1.5,2.0,2.5$, and 3.0). For each pair, the first distribution in all cases was the relevant reference distribution noted above and the second distribution was constructed by modifying the reference distribution so as to increase its mean and variance while leaving the associated level of social 
welfare unchanged under the assumed value of $\epsilon$. To minimize possible confounding, for both income and health the percentage increase in income (health) under policy B was constant across all the alternative distributions, which differed among themselves only in their degree of inequality. For income, the mean income for all alternative distributions was set to be $10 \%$ higher than that of the reference distribution; for health, the mean HALE for all alternative distributions was set to be $1 \%$ higher than that of the reference distribution. The mean change for HALE was set lower because a $10 \%$ change in life expectancy (about 7 years) was unrealistic.

The bi-variate distributions of income-related health were constructed using the same approach, but because they are bi-variate the assumed underlying social welfare function differed. For this case, we used the social welfare function underlying the Extended Concentration Index (ECI), as derived by Bleichrodt and van Doorslaer (2006), which allows for varying degrees of income-related health inequality aversion. Under common assumptions about preferences, plus a few specific to the bi-variate concentration index, an abbreviated social welfare function for the ECI is simply Wagstaff's (2002) achievement index, which can be written as:

$$
W_{E C I}=F(h)=\sum_{q=1}^{Q} \alpha_{q} h_{q}=\frac{\sum_{q=1}^{Q}\left(r_{q}^{\gamma}-\left(r_{q}-1\right)^{\gamma}\right) h_{q}}{Q^{\gamma}},
$$

where $\alpha_{q}$ is a social welfare weight for those in quintile $q, h_{q}$ is the health level of those in quintile $q$, and $r_{q}$ is the rank in terms of socioeconomic status. $\gamma$ reflects bivariate inequality aversion whereby $\gamma=1.0$ implies that everyone's health is weighted equally (classical utilitarian) and $\gamma=\infty$ implies that the health of only the worst off individual matters (Rawlsian). ${ }^{3}$ We constructed pairs of distributions associated with each of five levels of income-related inequality aversion $(\gamma=1.0,1.5,2.0,2.5$, and 3.0).

\subsection{The survey instrument and administration}

The survey instrument included three parts. The first part described the experimental context and presented the choice scenario. The second part elicited a measure of

\footnotetext{
${ }^{3}$ For the bi-variate case, it was challenging to hold the mean difference between the baseline and alternative distributions constant across all values of the aversion parameter while also equating welfare of each to the reference distribution, so mean health was allowed to vary slightly among the set of alternative distributions.
} 
participants' social values orientation. Previous studies of the association between individual characteristics and inequality attitudes has found generally weak associations, but perhaps the strongest and most consistent association - at least for income inequality - is an individual's political beliefs. We hypothesized that political beliefs reflect more fundamental values, and therefore chose to measure participants social values directly. To do so we used a validated measure of social values orientation (SVO) (Messick and McClintock, 1968; Liebrand and McClintock, 1988) that has been used previously in economics (Mentzakis and Mestelman, 2013; Hurley et al., 2017). The SVO instrument presents participants with a social values orientation (SVO) game which requires them to make a series of 24 hypothetical money-sharing decisions between themselves and an unknown person with whom they are randomly matched. Based on their SVO decisions, participants are classified into five value-orientations; altruistic (maximize the pay-off to the other person), cooperative (maximize joint pay-offs), individualistic (maximize their own payoff), competitive (maximize their own pay off relative to the other person), or aggressive (minimize the payoff to the other person). Finally, the third part of the survey elicited the participants' socio-economic and demographic characteristics.

The survey was administered to a representative sample (drawn by a marketing research firm) of the community-dwelling population of Ontario, Canada using a mixed-mode methodology. Individuals were invited to participate via a letter sent by regular post, but completed the survey online. Participants therefore had to have access to a computer and internet, but any adult member from the household was eligible to take part. Upon logging in, participants were randomly assigned to one of the 15 versions ( 3 domains with 5 levels of inequality aversion in each) of the survey. As an incentive to participate, respondents were told that they would be entered into a draw for $\$ 250$ (CAD) with guaranteed odds of at least 1 in 50 . Prior to administering the survey, we pilot-tested the survey in the McMaster Experimental Economics Laboratory using a sample of university-affiliated individuals including undergraduate students, graduate students and staff ranging in age 17 to 28. The study protocol was approved by the McMaster University Research Ethics Board.

\section{Empirical analysis}

We first examined descriptive statistics of the implied distribution of inequalityaversion values in the population, focusing on the median inequality-aversion value. We then estimated the inequality aversion parameter using a structural estimation approach within a random utility framework. 


\subsection{Descriptive analysis: median inequality aversion}

Survey responses provided an estimate of the lower or upper bound for each participant's inequality aversion. If a participant chose the lower-mean, lower-variance distribution (Policy A), the inequality-aversion value assumed in the construction of the distributions represents a lower-bound for the participant's inequality aversion. In contrast, if a participant chose the higher-mean, higher-variance distribution (Policy B), the inequality-aversion parameter value used in the construction of the distribution represents an upper bound for the participant's inequality aversion value. This information is insufficient to calculate the mean for the distribution of participant inequality-aversion values; it is possible, however, to identify the interval in which the median value falls, and this provides an estimate of the population value.

\subsection{Modeling inequality aversion within random utility}

Building from the social welfare foundation for the choice experiment, and the Random Utility (RUT) model that provides theoretical support to the analysis of choice data (McFadden, 1973), we adapted for our context an approach that has been used to estimate risk aversion using an Atkinson social welfare function (Harrison and Rutstrom, 2008), which enabled us to structurally estimate the mean value for inequality aversion in the population. ${ }^{4}$ For individual $i$ and distribution $j$, in a random utility model the individual indirect utility is

$$
U_{i j}=I_{i j}+v_{i j}
$$

where $I_{i j}=\sum_{q=1}^{Q} \frac{1}{e} y_{q}^{e}$ is the assumed social utility function that denotes the welfare associated with distribution $j$ (for a society of size $Q$ ), $y$ is the outcome of interest (income, health), and $e=1-\epsilon$ is the societal inequality aversion parameter. $v_{i j}$ is an error term, assumed to be extreme value type I distributed, that captures unobserved variation originating either from heterogeneity of preferences unknown to the analyst but known to the respondent or from mistakes in evaluation on the part of the individual. As with McFadden's (1973) RUT model, this formulation assumes independence of irrelevant alternatives. Maximizing utility, individual $i$ would favor

${ }^{4}$ In this context, "utility" refers to the social utility, or welfare, the participant assigns to the distributions. 
policy $A$ if:

$$
\begin{aligned}
P\left(A_{i}\right) & =P\left(U_{i A}>U_{i B}\right) \\
& =P\left(I_{i A}+v_{i A}>I_{i B}+v_{i B}\right) \\
& =P\left(v_{i}>-\left(I_{i A}-I_{i B}\right)\right) \\
& =\Lambda\left(I_{i A}-I_{i B}\right)
\end{aligned}
$$

where $v_{i}=v_{i A}-v_{i B}$ and $\Lambda($.$) is the logistic cumulative distribution function. { }^{5}$ Substituting the functional form of the indirect utilities, we have

$$
I_{i A}-I_{i B}=\sum_{q=1}^{Q} \frac{1}{e_{i}} y_{q A}^{e_{i}}-\sum_{q=1}^{Q} \frac{1}{e_{i}} y_{q B}^{e_{i}}=\frac{1}{e_{i}} \sum_{q=1}^{Q}\left(y_{q A}^{e_{i}}-y_{q B}^{e_{i}}\right) .
$$

This gives rise to a binary logit model with a non-linear non-continuous index function. Under the constraint that $e_{i} \neq 1$ (i.e., $\epsilon_{i} \neq 0$ ) the likelihood can be maximized with respect to $\epsilon{ }^{6}$ Given the non-linear index function, normalization of the scale of the distribution is not necessary but can be estimated as a parameter (i.e., $\sigma$ ), which allows for estimation of $\epsilon$ scale-free and comparable across models and samples. As such, the corresponding probability from the structural model specified for the income and health distributions is:

$$
P\left(A_{i}\right)= \begin{cases}\Lambda\left(\frac{\frac{1}{e} \sum y_{q A}^{e}-y_{q B}^{e}}{\sigma}\right) & \text { if } \quad e \neq 0 \quad(\text { i.e. } \quad \epsilon \neq 1) \\ \Lambda\left(\frac{\sum \ln \frac{y_{q A}}{y_{q B}}}{\sigma}\right) & \text { if } e=0 \quad(\text { i.e. } \quad \epsilon=1)\end{cases}
$$

For the bivariate income-health case, the same reasoning is followed for the bivariate social welfare function with the resulting probability being

$$
P\left(A_{i}\right)=\Lambda\left(\frac{\frac{\sum\left(r_{q}^{\gamma}-\left(r_{q}-1\right)^{\gamma}\right)\left(y_{q A}-y_{q B}\right)}{Q^{\gamma}}}{\sigma}\right)
$$

\footnotetext{
${ }^{5}$ Because the logistic distribution function is symmetric, this imposes a restriction that the mean and median estimates are the same.

${ }^{6} \mathrm{An}$ alternative formulation of the framework in $\epsilon$-space in which $\epsilon$ was modeled directly rather than using a structural model is presented (along with its results) in Appendix B. We draw only brief comparisons in the text.
} 
where $\gamma$ is the inequality aversion parameter, $r_{q}$ is the rank of the quintile in terms of socioeconomic status with $r_{q}=1$ referring to the richest quintile and $r_{q}=5$ to the poorest of the presented distribution.

Parameters were estimated through maximum likelihood (ML) with the following log-likelihood to be maximized

$$
\ln L=\sum_{i}^{N} \ln P\left(A_{i}\right)
$$

We examined heterogeneity in inequality-aversion values within the population in two ways. First, using split-sample estimation we compared mean inequality aversion across population sub-groups defined by socio-demographic characteristics. Second, for health-related inequality aversion, for which descriptive analyses indicated a highly bi-modal distribution of values in the population, we extended the structural estimation model to a latent class (LC) setting (Hurley et al., 2017). LC models probabilistically sort participants into $C$ classes, with each class denoting a different preference pattern. Class membership follows a multinomial logistic distribution where the probability that an individual $i$ falls in class $c$ is

$$
H_{i c}=\frac{e^{z_{i} \gamma_{c}}}{\sum_{c=1}^{C} e^{z_{i} \gamma_{c}}},
$$

where $z_{i}$ are individual-specific covariates that characterize the class membership. For the full model the contribution of individual $i$ to the likelihood is

$$
L_{i}=\sum_{c=1}^{C} H_{i c} \times P\left(A_{i}\right)
$$

with the following log-likelihood for sample size $N$ :

$$
\ln L=\sum_{i=1}^{N} \ln \left[\sum_{c=1}^{C} H_{i c} \times P\left(A_{i}\right)\right]
$$

To resolve convergence issues in the LC models we exploited the scale invariance of the Atkinson social welfare function and transform eq. (5) to capture the relative (rather than absolute) distance between the two presented distributions. This relative-distance reformulation produced identical aversion estimates (up to the fifth 
decimal) in the non-LC models, but enabled extension of the structural approach to the LC specification. The LC model was estimated through the Expectation Minimization (EM) algorithm that offered greater stability compared to maximum likelihood estimation. The steps of the EM algorithm for a latent class binary model are discussed in detail in Soete and DeSarbo (1991). Standard errors for the EM estimation were calculated through bootstrap with 250 replications.

Finally, to adjust for differences in observed socio-demographic characteristics between our experimental sample and the Ontario population, we developed poststratification weights for age and sex using the population estimates for the province of Ontario. Weights were calculated as a ratio of the Ontario population frequencies from the Canadian Community Health Survey, a representative sample of Ontario's community-dwelling population, and cell frequencies in our survey (see Appendix C for a description of the calculation of the post-stratification weights).

\subsection{Qualitative assessment of participants choice reasoning}

We used descriptive qualitative methods (Sandelowski, 2000, 2010) to identify common themes among participants' written explanations of their reasoning. Responses for each domain were sorted and coded separately. Within each, comments from participants who chose the more equal distributions were sorted and coded separately from those who chose the less equal distributions. The concepts to which the most comments aligned were identified as the common themes.

\section{Results}

Invitations for participation were mailed to 17,000 randomly selected communitybased residents of Ontario. Of these, 1964 individuals completed the choice scenario presented, for an overall response rate of 11.6 percent, which is typical for mixedmode, web-based surveys of this type (Dillman et al., 2014; Dillman, 2017). Of these respondents, $671(34.2 \%)$ completed the income scenario, 650 (33.1\%) completed the health scenario, and $643(32.7 \%)$ completed the bivariate income-health scenario. The vast majority of respondents $(N=1810,92 \%)$ completed the entire survey, while $8 \%(N=154)$ had some missing information regarding their individual characteristics.

Among the 1964 participants who completed the full survey, the average age is just under 60 years old, about three quarters are men, just under 80 percent are married, about 45 percent are employed full-time and 35 percent are retired, over three 
quarters are secondary school graduates and just under 43 percent have a university degree, 52 percent report a household income of over $\$ 75,000$ and 38 percent report a household income of over $\$ 100,000$, over 85 percent own their home, just under 57 percent report very good or excellent health, and value-orientation scores indicate that around 64 percent are cooperative or altruistic and nearly 22 percent as individualistic (Table 2). A comparison of characteristics of the income, health, and bi-variate sub-samples reveals no statistically significant differences, indicating that we have a balanced sample across domains. A comparison of our sample to the Ontario community-dwelling population reveals that although our sample tracks the population reasonably well with respect to self-assessed health, education, and employment, our sample is older, contains a higher proportion of men, a higher proportion of married individuals, a higher proportion of retirees, and a higher proportion of individuals reporting incomes greater than $\$ 100,000$. To at least partially address these differences, for the analyses we constructed estimation weights to enable re-weighting to match the sample to the population with respect to age and sex.

\subsection{Median inequality aversion}

Table 3 tabulates, for each of income, health and income-related health, the percentage of participants who chose Policy A (the more equal distribution in the pair) and the corresponding percentage who chose Policy B (the less equal distribution in the pair) for the choice scenario presented to them. Because choice of the more equal distribution (Policy A) indicates that the participant's inequality aversion is greater than that assumed when constructing the pair of distributions presented, the percentage choosing Policy A should decrease monotonically as the assumed $\epsilon$ value increases. The median inequality-aversion value falls in the interval between the $\epsilon$ values at which the majority of the sample changes from Policy A to Policy B.

For income, the percentage of participants choosing the more equal distribution declines from 72.6 percent for $\epsilon=1.0$ to 52.8 for $\epsilon=2.5$, in line with expectations. The percentage bumps up for $\epsilon=3.0$, though this value is not statistically different than that for 2.5, so the choices satisfy weak monotonicity whereby the percentage do not increase as $\epsilon$ increases. The distribution suggests a median value slightly greater than 3.0, slightly larger but consistent with previous studies using a similar distributional approach, which have obtained median estimates between 2 and 3 (Johansson-Stenman et al., 2002; Carlsson et al., 2005; Pirttila and Uusitalo, $2010)$. 
For health, the median value of inequality aversion falls between 1.0 and 1.5, but remarkably, just under 50 percent (49.18) have an aversion value less than 1.0 (consistent with weak inequality aversion or even inequality-loving preferences) and just under 50 percent (47.58) have an aversion value greater than 3.0, with very few participants having aversion values between 1.0 and 3.0, indicating a bi-modal distribution of preferences towards inequalities in health. This estimate is notably smaller than that obtained by previous UK studies (Dolan and Tsuchiya, 2011; Robson et al., 2017), though the estimates are not directly comparable because those studies presented distributions of income-related health inequality. However, our results are similar in magnitude to Attema et al. (2015) (median 1.5 or less), and are similar in two senses to Cropper et al.'s (2016). Over 30 percent of participants in Cropper et al. displayed lexicographic preferences, always choosing the more equal distribution, implying very high values of aversion, and although the bounds for the interval containing their median are large, they obtain a median $\epsilon$ estimate of between 1.75 and 4.9, with the median likely closer to 1.75 (just under 49 percent of respondents have a value less than 1.75 ).

For the bivariate income-health distribution, we observe a steeper decline in the percentage of participants preferring the more equal distribution (Policy A). In the bi-variate case, just under 20 percent hold inequality-loving preferences $(\gamma<1.0)$, and the proportion of participants choosing the more equal distribution declines from 80.3 percent to 37.0 percent over the range of $\gamma$ values of 1.0 and 3.0, with a median inequality aversion between 1.5 and 2.0. No previous study has estimated inequality aversion with respect to income-related health inequality within a bi-variate framework, but we would note that this estimate does not differ substantially from the assumed $\gamma$ value for the standard concentration index used in much health equity research (Fleurbaey and Schokkaert, 2012), which assumes $\gamma=2.0$ (Wagstaff, 2002). As we discuss in more detail below, although not directly comparable, this estimate implies notably less inequality aversion than the $\epsilon$ estimates obtained by Robson et al. (2017) and Dolan and Tsuchiya (2011) (10.95 and 28.9, respectively).

For all three cases we observe a small deviation from strict monotonicity as $\epsilon$ or $\gamma$ increases from 2.5 to 3.0, but in no cases are the differences statistically different, so again, the choices satisfy weak monotonicity whereby the proportions do not increase as $\epsilon(\gamma)$ increases. Given the single-shot and between-subject nature of our survey, this weaker assumption is sufficient. 


\subsection{Mean inequality aversion}

The top panel of Table 4 displays the mean inequality aversion estimates for each of the univariate distributions of income and health (i.e., based on eq. 6), and the bivariate distribution of income-related health (i.e., based on eq. 7). The estimated mean inequality aversion for income is $\epsilon=3.27$, for health is $\epsilon=1.17$ and for incomerelated health is $\gamma=1.66$. The estimate for income is statistically different from 0.0 (inequality neutral) at the $5 \%$ level, that for health is not, and the estimate for bivariate income-related health is statistically different from 1.0 (inequality neutral) significant at the $5 \%$ level.

The mean estimates for inequality aversion differ statistically and economically across the three domains. The mean aversion estimate of 3.27 for income implies an equally distributed equivalent (EDE) income (Atkinson, 1970) of $\$ 26,850$; or that society would be willing to give up $\sim 56 \%$ of mean income if the remainder were distributed equally. For health, given that the estimate is not statistically different from zero, one could argue that society is inequality neutral; but taking the mean estimate of 1.17 at face value implies an EDE of 69.8 health-adjusted life expectancy, only 0.3 percent less than the mean of the actual distribution. ${ }^{7}$ Finally, $\gamma=1.66$ for the bivariate income-health distribution implies an EDE of 67.9 health-adjusted life years, conditional on the assumed distribution of income, 3 percent less than the the mean health-expected life expectancy in the reference bivariate distribution. ${ }^{8}$ Further insight can be gained by examining the impact on the value of the extended concentration index of reducing the value of $\gamma$ from 2.0 (the value assumed for the standard concetration index) to 1.66. For the reference distribution used in the

\footnotetext{
${ }^{7}$ These estimates of the proportion of income or health society would be willing to give up reflect both the strength of inequality aversion and the variability in the distributions, which differed across income and health. To gain a better sense for the impact of the differing estimates, we applied each estimate to both distributions. For income, a mean aversion estimate of 1.17 implies an EDE of $\$ 45,288$, or a willingness to give up $26 \%$ of mean income if the remainder were distributed equally, less than half that for an aversion estimate of 3.27; for health, a mean aversion estimate of 3.27 implies an EDE of 69.4 , or a willingness to give up $0.8 \%$ of mean health-adjusted life expectancy, more than twice that for a mean estimate of 1.17 .

${ }^{8}$ Equating e.q. (2) with a bivariate distribution social welfare function with a common health allocation, EDE is calculated as
}

$$
h_{E D E}=\frac{\sum_{q=1}^{Q}\left(r_{q}^{\gamma}-\left(r_{q}-1\right)^{\gamma}\right) h_{q}}{Q^{\gamma}}
$$


survey, $\gamma$ of 1.66 implies a value of the ECI 27 percent less pro-rich (0.025 vs. 0.034) than when $\gamma=2.0 .^{9}$

\subsection{Heterogeneity in Mean Inequality Aversion by Socio-demographic Characteris- tics}

To assess heterogeneity in inequality-aversion estimates in the population, and its possible association with socio-demographic characteristics, the lower panel of Table 4 presents the estimates of mean inequality aversion derived from split-sample estimations, which avoids over-parameterization of the empirical model. Sub-samples were created by dichotomously defining socio-economic and demographic characteristics, as described in the notes to the table. For those variables with original definitions that included more than two categories, testing alternative cut-off points for the dichotomization made no difference to the results.

For income we find no meaningful heterogeneity in estimates of mean inequality aversion across the characteristics of participants. All estimates oscillate around the full-sample estimate of 3.27, the differences are often small in absolute terms, and in no cases do the estimates across sub-samples differ statistically. The split-sample estimates for health suggest some heterogeneity, though even here the differences observed are not statistically significant at conventional levels. Health-related inequality aversion is less for those under age 60 compared to those over age 60 (1.00 vs. 6.41), those in poor health compared to those in good health (1.05 vs. 1.89), those with less education compared to those with more education (0.58 vs. 4.15) and those with household income less than $\$ 75,000$ compared to those with household income greater than $\$ 75,000$ (0.95 vs. 2.28). But again, large standard errors render these large absolute differences non-statistically significant. Finally, for the bi-variate, the sub-sample estimates oscillate around the full-sample estimate of 1.66, with the small differences in absolute terms, but in some cases these differences are statistically significant. The estimates for each income sub-sample (1.98 and 1.47 respectively for those below and above $£ 75 \mathrm{~K}$ ) differ from the overall mean at the $10 \%$ level and differ from each other at the $1 \%$ level. The estimates for those below age 60 are slightly larger than those above age 60 (1.86 vs 1.54) at the $10 \%$ level, and

\footnotetext{
${ }^{9}$ As an alternative indicator, using microdata from the Canadian Community Health Survey for Ontario regarding health-related quality-of-life, as measured by the Health Utilities Index Mark 3 (HUI3) (Horsman et al., 2003), the estimate of income-related health inequality is 22 percent less pro-rich (0.0154 vs. 0.019).
} 
the estimates for those employed full-time are slightly smaller than those not employed full-time (1.51 vs. 1.88) at the $1 \%$ level. Nevertheless, in all cases translating mean differences to EDEs reveals that heterogeneity in values has minimal economic implications.

\subsection{Robustness checks}

As a robustness check we also estimated mean inequality-aversion values by directly modeling the distribution of implied inequality aversion values (for details see Appendix B). Overall, the findings from this direct estimation approach corroborate the structural estimates. For all three domains, the estimate of the mean inequalityaversion from the direct approach are slightly larger than the structural estimate, which might be an artefact of the open-interval (i.e., left- and right-censored intervals) nature of the information elicited from the choice experiment, but they follow the same pattern and are of similar magnitude to the structural estimates, i.e. mean inequality aversion of 4.4 for income, 1.2 for health, and 2.0 for income-related health, again with only the estimates for income and income-related health statistically different from risk neutrality (0.0 and 1.0, respectively). The direct approach estimated on split samples also replicated the key findings with respect to heterogeneity across socio-economic and demographic characteristics. See Table B1 for the full set of estimates.

Structural estimates obtained using weighted estimation to mitigate issues of selection with respect to the Ontario population are almost identical to the unweighted estimates (which is not surprising given weak associations between aversion estimates and observable characteristics), though now the estimates of $\epsilon$ are statistically significant for both income and health rather than just income (and $\gamma$ remains statistically significant for income-related health). Table C3 in Appendix C presents the weighted estimates.

\subsection{Unobserved heterogeneity}

To further explore heterogeneity in inequality aversion across the sample, we embedded the structural approach within a latent class specification to capture systematic unobserved heterogeneity. The latent-class structural specifications failed to converge for the income and bivariate distributions, which is consistent with the relative lack of strong variation present in the median and mean estimates. For the health

distribution, which we were particularly interested in exploring given the bi-modal 
distribution observed in the descriptive analysis, we estimated a latent-class specification with two classes (Table 5). Consistent with our earlier results, none of the socio-economic and demographic characteristics contribute to explaining class membership, and the two classes are of nearly equal size (0.493 and 0.507). As expected, one of the classes (Class 1) exhibits a large aversion to health inequality, with an estimated mean of $\epsilon=7.3$ (i.e. $E D E=68.7$ and $A(\epsilon)=1.7 \%$ ), whereas the second class (Class 2) exhibits small and not statistically significant aversion to health inequality: $\epsilon=0.3$ (i.e. $E D E=69.9$ and $A(\epsilon)=0.1 \%$ ) indicating very high tolerance for inequality and almost no willingness to trade mean health-adjusted life years to reduce inequality.

\section{Participant reasoning}

The survey asked each study participant why they chose the policy they did and provided an open-ended space in which to provide a written explanation for their choice. Over $90 \%$ of participants (94\% for income, $92 \%$ for health, and $94 \%$ for bivariate) explained their reasoning. This high level of engagement and the comments themselves confirm that the vast majority of participants took the exercise seriously, that they understood the exercise, and that their choices reflected a real attempt to reason through the exercise. The dominant patterns of reasoning were similar across domains. More striking were the differences in reasoning between those with differing degrees of inequality aversion. Accordingly, the analysis below examines separately the reasoning of the more-averse participants who chose the more-equal distribution (Policy A) of the pair presented and the less-averse participants who chose the less-equal distribution (Policy B).

Among those who chose the lower-mean, more-equal distribution, the two most common rationales cluster into two themes: concern for inequality (35 percent of those who provided a written explanation) and concern for the worst-off, those in the lowest quintile (29 percent) (Table 6). Those who appealed to the former expressed an egalitarian sensibility, and tended to speak about the whole distribution without necessarily referring to the impact of the policies on any specific quintiles. They used terms such as "more fair", "more equitable", "more even", "less disparity", "smaller range", or cognate terms. In contrast, those who based their choice on the outcomes of those in the lowest quintiles focused specifically on the experience of those in the lower part of the distribution rather than the distribution as a whole. Here, some used language that was explicitly Rawlsian ("We should be judged by how we treat the least fortunate among us"), while others focused on the two lowest 
quintiles together, referring more generally to a concern for those who are relatively disadvantaged.

Among those who chose the higher-mean, less equal distribution, the two most common rationales cluster into two themes: opportunity (25 percent of those who provided a written explanation) and higher mean (27 percent). Those who appealed to the former emphasized the importance of giving people the opportunity to earn higher incomes or to live longer. This reasoning focused very much on the top-end of the distribution and giving people a chance to attain these higher levels of outcomes. The other most common rationale pertained to the desirability of improving mean health in society. Here, while some used explicitly utilitarian reasoning ("I don't think any particular expectancy group is more entitled to benefit from health care policy than any other. Therefore, the only meaningful measure is the overall average health level."), most simply made reference to the goal of increasing the level of health in society.

Participants' explanations of their reasoning reveal more general similarities and differences in reasoning styles across the two groups. Perhaps the most notable similarity among those with differing aversion attitudes is the mixture of both instrumental reasoning and deontological reasoning (both across and within participants' comments). For instance, among those choosing the more equal distribution because of a focus on helping those in the lower quintiles, some emphasize our obligation to help those less well off in society while others reasoned that improving their health would enable them to work more and thereby generate broader benefits for society. Similarly, among those emphasizing improving the position of those at the top end of the distribution, some argue for the right to a long life or to the benefits of hard work, while others argue that such benefits for those at the top end will ultimately benefit those at all levels through a trickle-down process. With both groups (more averse/ less averse), subsets of participants explicitly appeal to some type of weighting function that acknowledges that groups benefit to differing degrees and in which, in the end, they judge the overall weighted benefits associated with their choice to exceed those of the alternative distribution. A few important differences stand out. Not surprisingly, those choosing the more equal-distribution more frequently appeal to notions of need while those choosing the less-equal distribution more frequently appeal to notions of reward. Individuals choosing the more-unequal distribution more frequently appealed to dynamic reasoning, about how over time the greater inequality is worth it because it would ultimately benefit everyone. Interestingly, although infrequent, some of those choosing the more-unequal distribution that benefited the higher quintiles acknowledged that they judged themselves to be members 
of the higher quintile groups in Canada, and so their choices may have reflected a certain self-interested affinity with those in such groups in the hypothetical society. No such references occur among those choosing the more-equal distribution with a focus on benefits to those in the lower-quintiles.

\section{Discussion}

Previous scholars (e.g. Tobin, 1970; Anand, 2002) have posited that inequality aversion would be greater toward health than income, and recent UK survey data are suggestive of this (Howarth et al., 2018). Ours is the first published study of which we are aware that estimates inequality aversion for univariate distributions of income and health using a consistent approach that enables their comparison and that extends consideration to bi-variate income-related health. We find substantial heterogeneity in inequality aversion both within and across income and health. Our findings indicate that the public is, on average, more averse to inequality in the distribution of income than inequality in the distribution of health, but more importantly, we find the distribution of inequality-aversion values for income and health to be quite different, rendering a simple comparisons of means of questionable value. The distribution of inequality- aversion values for health is highly bi-modal - distinct from that for income and that for bi-variate income-health - with nearly equal proportions of the participants with very low aversion $(\epsilon<1.0)$ and or with very high aversion $(\epsilon>3.0)$. Mean estimates of inequality aversion for these two groups are 0.34 and 7.30 respectively. The written explanations participants provided regarding the reason for their choices confirms that the participants understood the choice problem and chose according to their expressed values. Although direct comparison is not possible, this bi-modal distribution is broadly consistent with Cropper et al.'s (2016) study of inequality aversion toward univariate distributions of health risks, which found that over 30 percent of participants exhibited extreme inequality aversion that the authors classified as lexicographic because the participant always chose the more equal distribution. This finding of a bi-modal distribution of inequalityaversion values - or at least a distribution with a very thick upper tail-deserves further investigation, as it appears distinct from that for income.

The estimates of inequality aversion towards income-related health inequality are not directly comparable to those estimates for univariate income and health. Again, to our knowledge, ours are the first estimates of bi-variate income-related inequality aversion estimated within a consistent bi-variate social welfare framework. We obtain estimates of a median inequality aversion of 1.5-2.0 and a mean equal to 1.66. 
To place these in context, the widely applied Concentration Index of bivariate inequality assumes a value of 2.0, and for both the bi-variate reference distribution of income-related health-adjusted life-expectancy and for the distribution of healthrelated quality-of-life (Health Utilities Index), the mean estimate of 1.66 leads to estimates for pro-rich inequality approximately 25 percent less than under the assumed value of 2.0. Other studies of inequality aversion toward bi-variate income-related health provide estimates based on the univariate Atkinson Index. That is, they implicitly ignore the two-dimensional nature of the distribution presented to participants. The resulting estimates are highly variable, but all very large (e.g., median $\epsilon$ $=10.95$ and 28.9 in Robson (2017) and Dolan and Tsuchiya (2011)). If we similarly apply the Atkinson framework to the observed choice over the bi-variate distribution used in this study, the implied median Atkinson inequality-aversion parameter $(\epsilon)$ is between 3.2 and 6.9; large, but notably smaller than estimates from the UK studies cited above. Comparing this median estimate to that for the univariate health distribution reveals that inequality aversion to income-related health inequality exceeds that for health inequality per se (median 3.2-6.9 vs. 1.0-1.5). This is consistent both with other data (Howarth et al., 2018), and with the focus of much of the health inequality literature on the bivariate association between socio-economic status and health inequalities (Asada, 2013). This may be due to the fact that some sources of inequality in the univariate distribution of health (e.g., health-related behaviours such as smoking or diet) are not perceived by some as unfair, while income-related inequality is perceived by many as unfair. Further work should be undertaken to understand the relationship between aversion to univariate and bi-variate health inequalities.

For some years there has been a debate in the health inequalities literature regarding which health distribution - univariate health or bivariate socio-economic-related health - should be the focus of policy concern in the health sector. Those who advocated for a focus on the univariate health distribution argued that what matters most is inequality among people regarding the likelihood of living a long, healthy life, regardless of how that might vary with socio-economic characteristics (Murray et al., 1999; Wolfson, 2001). In contrast, those who advocated for a focus on the bivariate socio-economic-related health distribution argued that the question of whether inequality in the likelihood of a long, healthy life varies with a person's socio-economic status is of primary importance, as it implies a form of inequity that pure variation does not (Braveman and Gruskin, 2003; Marmot, 2013). While the univariate health distribution will in many instances be an object of interest, our results indicate that the public is more concerned about inequalities that are systematically related to a persons socio-economic status, lending support to a policy focus on the bivariate 
relationship.

Although we find some differences in inequality-aversion preferences by participants' characteristics, in general such characteristics explain little of the variation in choices. Even social values orientation - an attitudinal measure never previously included in studies of inequality aversion - somewhat surprisingly, fails to correlate with inequality aversion. Previous analyses of the associations between inequality aversion and socio-economic and demographic characteristics is mixed, but in general, few consistent patterns emerge, with the possible exception of that with political beliefs (Johansson-Stenman et al., 2002; Pirttila and Uusitalo, 2010). Recent studies from social psychology regarding attitudes towards income and wealth inequality similarly find very weak association between individual characteristics and inequality preferences (Norton and Ariely, 2011; Kiatpongsan and Norton, 2014). The weak association between individual characteristics and inequality attitudes stand in contrast to those for redistributional preferences, for which socio-economic, demographic and political attitudes correlate strongly with preferences for redistribution (Alesina and LaFerrara, 2005; Alesina and Giuliano, 2011). The reasons for such differences across such closely related issues deserve further investigation.

These estimates imply potentially large welfare gains from reducing inequalities in these domains. The well-established bi-directional causal relationships between income and health imply that coordinated policies across the domains have the potential to simultaneously reduce inequalities in both. Economic displacement and lack of income and other economic resources can negatively affect physical and psychological health, lead to health-harming behaviours, and impede access to care that can ameliorate health problems; at the same time, poor health compromises individuals' ability to invest in human capital when young and earn income during the working ages, decreases income and economic opportunities throughout the lifespan (Smith, 2003; Cutler and Lleras-Muney, 2008; Currie, 2009). The assessment of policies that act on both should therefore take into account the effects on inequalities in each.

In closing, we note some potential limitations to our design and areas for future research. Some differences across the scenarios in the income and health domains may have contributed to the differences we observe in inequality-aversion estimates across the domains. In the monetary domain, the outcome - annual income - is a flow measure, while in the health domain the outcome - health-adjusted life-expectancy - is a stock measure. We chose these measures because of their familiarity to the general public and because they are the most commonly used outcome measures in the two literatures most closely related to our study. It is possible, however, that this 
difference influenced responses. The literature on attitudes toward economic inequality includes studies of aversion to income inequality (flow) and aversion to wealth inequality (stock), but to our knowledge no study has directly compared whether attitudes differ for the two. Future research could examine directly whether attitudes differ systematically between flow measures and stock measures. Furthermore, health-adjusted life-expectancy is only one of several possible measures of health; it is unknown how generalizable findings for this measure are to other measures of health. The degree of variability in the distributions presented was larger in the income domain than in the health domain (e.g., extremal quotient of 9.3 in the reference distribution for income and 1.2 in the reference distribution for health); further, Policy B increased the average income by 10 percent in the income domain but 1 percent in the health domain. We faced a trade-off between presenting realistic distributions/changes in the respective domains versus complete standardization of the scenarios. The reality is that there is substantially greater variability in the distribution of income than in the distribution of life expectancy. Similarly, realistic changes for the distributions differ: a 1 percent change in income would be seen as trivial; a 10 percent (7-year) increase in health-adjusted life-expectancy over a few years would be unrealistically large. Because our design and analysis were based on the response to a single scenario, participant responses were not influenced by a direct comparison across the two domains. Again, future research could examine the impact of large and small changes/differences in distributions on measured aversion. Finally, our objective was to measure inequality aversion across domains. To do so, we employed a standard social welfare approach from economics. This approach, however, cannot formally model a broader range of equity concerns (e.g., individual responsibility, fair innings, age-weighting) commonly identified as relevant to the full assessment of distributional fairness or equity of income or health distributions. .

\section{Acknowledgements}

This research was funded by grant \#2045 from the Government of Ontario through the Ministry of Health and Long-Term Care Health System Research Fund. The views expressed in this paper are those of the authors and should not be taken to represent the views of the Government of Ontario. We thank two anonymous reviewers, Neil Buckley, Paul Contoyannis, Kate Cuff, David Feeny, Michel Grignon and Stuart Mestelman for helpful comments and David Cameron and Gioia Buckley for assistance implementing the survey. 


\section{References}

Alesina, A. and Giuliano, P. (2011). Preferences for Redistribution. In Benhabib, J., Bisin, A., and Jackson, M., editors, Handbook of Social Economics, pages 93-131. Elsevier B.V., Amsterdam.

Alesina, A. and LaFerrara, E. (2005). Preferences for Redistribution in the Land of Opportunities. Journal of Public Economics, 89(5-6):897-931.

Alexander, S. S. (1974). Social Evaluation Through Notional Choice. Quarterly Journal of Economics, 88(4):597-624.

Amiel, Y., Creedy, J., and Hurn, S. (1999). Measuring Attitudes Towards Inequality. Scandanavian Journal of Economics, 101(1):83-96.

Anand, S. (2002). The Concern for Equity in Health. Journal of Epidemiology and Community Health, 56(7):485-487.

Asada, Y. (2013). A Summary Measure of Health Inequalities: Incorporating Group and Individual Inequalities. In Eyal, N., Hurst, S., Norheim, O., and Wikler, D., editors, Inequalities in Health: Concepts, Measures, and Ethics, pages 37-52. Oxford University Press, Oxford, UK.

Atkinson, A. B. (1970). On the Measurement of Inequality. Journal of Economic Theory, 2(3):244-263.

Attema, A., Brouwer, W., L'Haridon, O., and Into, J. L. (2015). Estimating SignDependent Societal Preference for Quality of Life. Journal of Health Economics, 43(September):229-243.

Bleichrodt, H. and van Doorslaer, E. (2006). A Welfare Economics Foundation for Health Inequality Measurement. Journal of Health Economics, 25(5):945-957.

Blundell, R., Joyce, R., Norris Keller, A., and Ziliak, J. (2018). Income Inequality and the Labour Market in Britain and the US. Journal of Public Economics, 162:48-62.

Braveman, P. and Gruskin, S. (2003). Defining Equity in Health. Journal of Epidemiology and Community Health, 57(4):254-258.

Buck, D., Baylis, A., Dougall, D., and Robertson, R. (2018). A Vision for Population Health. The King's Fund, London. 
Camerer, C. F. and Fehr, E. (2006). When Does "Economic Man Dominate Social Behaviour? Science, 311(5757):47-52.

Carlsson, F., Daruvala, D., and Johansson-Stenman, O. (2005). Are People Inequality-Averse or Just Risk-Averse? Economica, 72(285):375-396.

Charness, G. and Rabin, M. (2002). Understanding Social Preferences with Simple Tests. Quarterly Journal of Economics, 117(3):817-869.

Chetty, R., Stepner, M., Abraham, A., Lin, S., Scuderi, B., Turner, N., Bergeron, A., and Cutler, D. (2016). The Association Between Income and Life Expectancy in the United States, 2001-2014. Journal of the American Medical Association, 315(16):1750-1766.

Costa-Font, J. and Cowell, F. (2019). Incorporating Inequality Aversion in HealthCare Priority-Setting. Social Justice Research, 32:172-185.

Cowell, F. and Schokkaert, E. (2001). Risk Perceptions and Distributional Judgments. European Economic Review, 45(4):941-952.

Cropper, M., Krupnik, A., and Raich, W. (2016). Preferences for Equality in Environmental Outcomes. NBER Working Paper 22644, Cambridge, MA.

Currie, J. (2009). Healthy, Wealthy, and Wise: Socioeconomic Status, Poor Health in Childhood, and Human Capital Development. Journal of Economic Literature, 47(1):87-122.

Cutler, D. and Lleras-Muney, A. (2008). Education and Health: Evaluating Theories and Evidence. In House, J., Schoeni, R., Kaplan, G., and Pollack, H., editors, Making Americans Healthier: Social and Economic Policy as Health Policy. Russell Sage Foundation, New York.

Davidovitz, L. and Kroll, Y. (2004). On the Attitude Towards Inequality. In Cowell, F., editor, Inequality, Welfare and Income Distribution: Experimental Approaches, pages 137-147. Elsevier Limited, London.

Dillman, D. A. (2017). The Promise and Challenge of Pushing Respondents to the Web in Mixed-mode Surveys. Survey Methodology.

Dillman, D. A., Smyth, J. D., and Christian, L. M. (2014). Internet, Phone and Mixed-Mode Surveys: The Tailored Design Method. John Wiley, Hoboken, NJ, 4th edition. 
Dolan, P. and Tsuchiya, A. (2011). Determining the Parameters in a Social Welfare Function using Stated Preference Data: An Application to Health. Applied Economics, 43(8):2241-2250.

Einav, B. L., Finkelstein, A., Pascu, I., and Cullen, M. R. (2012). How General Are Risk Preferences? Choices under Uncertainty in Different Domains. American Economic Review, 102(6):2606-2638.

Fehr, E. and Schmidt, K. (1999). A Theory of Fairness, Competition, and Cooperation. The Quarterly Journal of Economics, 114(3):817-868.

Fleurbaey, M. and Schokkaert, E. (2012). Equity in health and health care. In Pauly, M., McGuire, T., and Barros, P., editors, Handbook of Health Economics, Volume 2, pages 1003-1092. North-Holland, Waltham, MA.

Garbinti, B., Goupille-Lebret, J., and Piketty, T. (2018). Income Inequality in France, 1900-2014: Evidence from Distributional National Accounts. Journal of Public Economics, 162:63-77.

Harrison, G. and Rutstrom, E. (2008). Risk Aversion in the Laboratory. Research in Experimental Economics, 12:41-196.

Horsman, J., Furlong, W., Feeny, D., and Torrance, G. (2003). The Health Utilities Index (HUI@): Concepts, Measurement Properties and Applications. Health and Quality of Life Outcomes, 1:54.

Howarth, D., Martraeu, T., Coutts, A., and Huppert, J. (2018). What do the British Public Think of Inequality in Health, Wealth, and Power. Social Science \& Medicine, 222:198-206.

Hurley, J., Mentzakis, E., Giacomini, M., DeJean, D., and Grignon, M. (2017). Nonmarket Resource Allocation and the Public's Interpretation of Need: an Empirical Investigation in the Context of Health Care. Social Choice and Welfare, 49(1).

Johansson-Stenman, O., Carlsson, F., and Daruvala, D. (2002). Measuring Future Grandparents' Preferences for Equality and Relative Standing. The Economic Journal, 112(479):362-383.

Kiatpongsan, S. and Norton, M. (2014). How Much (More) Should CEOs Make? A Universal Desire for More Equal Pay. Perspectives on Psychological Science, $9(6): 587-593$. 
Kroll, Y. and Davidovitz, L. (2003). Inequality Aversion versus Risk Aversion. Economica, 70(1):19-29.

Liebrand, W. B. G. and McClintock, C. G. (1988). The Ring Measure of Social Values: A Computerized Procedure for Assessing Individual Differences in Information Processing and Social Value Orientation. European Journal of Personality, 2(3):217-230.

Marmot, M. (2013). Fair Society Healthy Lives. In Inequalities in Health: Concepts, Measures, and Ethics, pages 283-298. Oxford University Press, Oxford, UK.

McFadden, D. (1973). Conditional Logit Analysis of Qualitative Choice Behavior. In Zarembka, P., editor, Frontiers in \{Econometrics\}, pages 105-142. Academic Press, New York.

Mentzakis, E. and Mestelman, S. (2013). Hypothetical Bias in Value Orientation Ring Games. Economics Letters, 120(3):562-565.

Messick, D. M. and McClintock, C. G. (1968). Motivational bases of choice in experimental games. Journal of Experimental Social Psychology, 4(1):1-25.

Murphy, S. L., Xu, J. Q., Kochanek, K. D., and Arias, E. (2018). Mortality in the United States 2017. National Centre for Health Statistics, Data Brief No 328, Hyattsville, MD.

Murray, C., Gakidou, E., and Frenk, J. (1999). Health Inequalities and Social Group Differences: What Should we Measure? Bulletin of the World Health Organization, 77(7):537-543.

Norton, M. and Ariely, D. (2011). Building a Better America - One Wealth Quintile at a Time. Perspectives on Psychological Science, 6(1):9-12.

Okun, A. (1975). Equality and Efficiency: The Big Tradeoff. Brookings Institute Press, Washington, D. C.

Parliament of Canada (2013). Income Inequality in Canada: An Overview. Technical Report Standing Committee on Finance, 41st Parliament, 2nd Session.

Piketty, T. (2013). Capital in the Twenty-First Century. Harvard University Press, Cambridge MA.

Pirttila, J. and Uusitalo, R. (2010). A 'Leaky Bucket' in the Real World: Estimating Inequality Aversion using Survey Data. Economica, 77(310):60-76. 
Robson, M., Asaria, M., Cookson, R., Tsuchiya, A., and Ali, S. (2017). Eliciting the Level of Health Inequality Aversion in England. Health Economics, 26(10):13281334.

Sandelowski, M. (2000). Focus on Research Methods Whatever Happened to Qualitative Description? Research in Nursing and Health, 23:334-340.

Sandelowski, M. (2010). What's in a Name? Qualitative Description Revisited. Research in Nursing and Health, 33:77-84.

Smith, J. P. (2003). Healthy Bodies and Thick Wallets: The Dual Relation Between Health and Economic Status. The Journal of Economic Perspectives, 13(2):145166.

Soete, G. D. and DeSarbo, W. S. (1991). A latent class probit model for analyzing pick any $/\{\mathrm{N}\}$ data. Journal of Classification, 8(1):45-63.

Statistics Canada (2011). Health-adjusted Life Expectancy, at Birth and at Age 65, by Sex and Income group, Canada and Provinces, Occasional (years). Technical report, Ottawa, ON, Canada.

Thurow, L. (1971). Income Distribution as a Public Good. Quaterly Journal of Economics, 85(3):327-336.

Tobin, J. (1970). On Limiting the Domain of Inequality. Journal of Law and Economics, 13(2):263-277.

Wagstaff, A. (2002). Inequality Aversion, Health Inequalities and Health Achievement. Journal of Health Economics, 21(4):627-641.

Williams, A. and Cookson, R. (2000). Equity in Health. In Culyer, A. J. and Newhouse, J. P., editors, Handbook of Health Economics, pages 1863-1910. NorthHolland, Amsterdam.

Wolfson, M. (2001). On Measuring Inequalities in Health. Rowe, G., 79(6):553-560. 


\section{Tables}

Table 1: Constructed Income, Health, and Income-related Health distributions

\section{Panel 1: Univariate Income}

Reference

$\epsilon=1.0$

$\epsilon=1.5$

$\epsilon=2.0$

$\epsilon=2.5$

$\epsilon=3.0$

\begin{tabular}{cccccc} 
Quintile 1 & Quintile 2 & Quintile 3 & Quintile 4 & Quintile 5 & Mean \\
\hline$\$ 14,600$ & $\$ 32,700$ & $\$ 49,700$ & $\$ 73,500$ & $\$ 135,500$ & $\$ 61,200$ \\
$\$ 12,200$ & $\$ 30,700$ & $\$ 49,700$ & $\$ 75,500$ & $\$ 168,500$ & $\$ 67,320$ \\
$\$ 13,900$ & $\$ 32,000$ & $\$ 49,700$ & $\$ 74,300$ & $\$ 166,700$ & $\$ 67,320$ \\
$\$ 14,200$ & $\$ 32,300$ & $\$ 49,700$ & $\$ 73,900$ & $\$ 166,500$ & $\$ 67,320$ \\
$\$ 14,400$ & $\$ 32,700$ & $\$ 49,700$ & $\$ 73,500$ & $\$ 166,300$ & $\$ 67,320$ \\
$\$ 14,550$ & $\$ 32,700$ & $\$ 49,700$ & $\$ 73,500$ & $\$ 166,100$ & $\$ 67,310$
\end{tabular}

\section{Panel 2: Univariate Health}

Reference

$\epsilon=1.0$

$\epsilon=1.5$

$\epsilon=2.0$

\begin{tabular}{cccccc} 
Quintile 1 & Quintile 2 & Quintile 3 & Quintile 4 & Quintile 5 & Mean \\
\hline 63.0 & 67.0 & 70.0 & 73.0 & 77.0 & 70.0 \\
55.0 & 64.5 & 70.0 & 76.0 & 88.0 & 70.7 \\
57.2 & 64.5 & 70.0 & 76.0 & 86.0 & 70.7 \\
59.1 & 64.5 & 70.0 & 76.0 & 84.0 & 70.7 \\
60.1 & 64.5 & 70.0 & 76.0 & 83.0 & 70.7 \\
61.2 & 64.5 & 70.0 & 76.0 & 82.0 & 70.7
\end{tabular}

$\epsilon=3.0$

Panel 3: Bivariate Income/Health

Income-Level

Reference

$\gamma=1.0$

$\gamma=1.5$

$\gamma=2.0$

$\gamma=2.5$

Quintile 1 Quintile 2 Quintile 3 Quintile 4 Quintile 5 Mean

$\gamma=3.0$

\begin{tabular}{cccccc}
$\$ 14,600$ & $\$ 32,700$ & $\$ 49,700$ & $\$ 73,500$ & $\$ 135,500$ & \\
64.0 & 67.0 & 70.0 & 73.0 & 76.0 & 70.0 \\
54.0 & 60.0 & 70.0 & 80.0 & 86.0 & 70.0 \\
56.8 & 67.0 & 70.0 & 80.0 & 86.0 & 72.0 \\
60.6 & 67.0 & 70.0 & 80.0 & 86.0 & 72.7 \\
62.2 & 67.0 & 70.0 & 80.0 & 86.0 & 73.0 \\
63.0 & 67.0 & 70.0 & 80.0 & 86.0 & 73.2 \\
\hline
\end{tabular}


Table 2: Sample Characteristics $(\mathrm{N}=1964)$

\begin{tabular}{|c|c|c|c|c|c|c|c|c|c|}
\hline & \multicolumn{2}{|c|}{ Income } & \multicolumn{2}{|c|}{ Health } & \multicolumn{2}{|c|}{ Bivariate } & \multicolumn{2}{|c|}{ Total } & \multirow{2}{*}{$\begin{array}{r}\text { Ontario } \\
\end{array}$} \\
\hline & $\mathrm{N}$ & $\%$ & $\mathrm{~N}$ & $\%$ & $\mathrm{~N}$ & $\%$ & $\mathrm{~N}$ & $\%$ & \\
\hline \multicolumn{10}{|l|}{ Age } \\
\hline$\leq 45$ & 80 & 11.9 & 67 & 10.3 & 87 & 13.5 & 234 & 11.9 & 50.0 \\
\hline $45-64$ & 333 & 49.6 & 314 & 48.3 & 309 & 48.1 & 956 & 48.7 & 32.5 \\
\hline$\geq 65$ & 193 & 28.8 & 208 & 32.0 & 201 & 31.3 & 602 & 30.7 & 17.4 \\
\hline No response & 65 & 9.7 & 61 & 9.4 & 46 & 7.2 & 172 & 8.8 & - \\
\hline \multicolumn{10}{|l|}{ Sex } \\
\hline Male & 477 & 71.1 & 453 & 69.7 & 471 & 73.3 & 1401 & 71.3 & 48.8 \\
\hline Female & 127 & 18.9 & 137 & 21.1 & 119 & 18.5 & 383 & 19.5 & 51.2 \\
\hline No response & 67 & 10.0 & 60 & 9.2 & 53 & 8.2 & 180 & 9.2 & - \\
\hline \multicolumn{10}{|l|}{ Marital Status } \\
\hline Single (never married) & 29 & 4.3 & 31 & 4.8 & 36 & 5.6 & 96 & 4.9 & 30.9 \\
\hline Married/Common-law & 516 & 76.9 & 507 & 78.0 & 498 & 77.5 & 1521 & 77.4 & 57.1 \\
\hline Divorced/Separated/Widowed & 59 & 8.8 & 52 & 8.0 & 59 & 9.2 & 170 & 8.7 & 11.8 \\
\hline No response & 67 & 10.0 & 60 & 9.2 & 50 & 7.8 & 177 & 9.0 & - \\
\hline \multicolumn{10}{|l|}{ Education } \\
\hline$<$ Secondary & 18 & 2.7 & 24 & 3.7 & 21 & 3.3 & 63 & 3.2 & 5.3 \\
\hline Secondary Graduate & 104 & 15.5 & 86 & 13.2 & 95 & 14.8 & 285 & 14.5 & 14.4 \\
\hline Post-secondary Graduate & 189 & 28.2 & 206 & 31.7 & 188 & 29.2 & 583 & 29.7 & 32.3 \\
\hline University Graduate & 287 & 42.8 & 266 & 40.9 & 289 & 45.0 & 842 & 42.9 & 43.7 \\
\hline No response & 73 & 10.9 & 68 & 10.5 & 50 & 7.8 & 191 & 9.7 & - \\
\hline \multicolumn{10}{|l|}{ Employment Status } \\
\hline Full-time & 306 & 45.6 & 270 & 41.5 & 302 & 47.0 & 878 & 44.7 & 47.9 \\
\hline Part-time & 46 & 6.9 & 50 & 7.7 & 37 & 5.8 & 133 & 6.8 & 10.2 \\
\hline Not Employed & 22 & 3.3 & 31 & 4.8 & 21 & 3.3 & 74 & 3.8 & 11.7 \\
\hline Retired & 224 & 33.4 & 229 & 35.2 & 230 & 35.8 & 683 & 34.8 & 16.6 \\
\hline No response & 73 & 10.9 & 70 & 10.8 & 53 & 8.2 & 196 & 10.0 & - \\
\hline \multicolumn{10}{|l|}{ Household Income } \\
\hline$<20,000$ & 14 & 2.1 & 17 & 2.6 & 16 & 2.5 & 47 & 2.4 & 6.6 \\
\hline $20,000-49,999$ & 64 & 9.5 & 83 & 12.8 & 67 & 10.4 & 214 & 10.9 & 26.5 \\
\hline $50,000-74,999$ & 119 & 17.7 & 88 & 13.5 & 109 & 17.0 & 316 & 16.1 & 20.6 \\
\hline $75,000-99,999$ & 93 & 13.9 & 101 & 15.5 & 96 & 14.9 & 290 & 14.8 & 20.2 \\
\hline$\geq 100,000$ & 252 & 37.6 & 243 & 37.4 & 243 & 37.8 & 738 & 37.6 & 26.1 \\
\hline No response & 129 & 19.2 & 118 & 18.2 & 112 & 17.4 & 359 & 18.3 & - \\
\hline \multicolumn{10}{|l|}{ Dwelling Status } \\
\hline Own & 569 & 84.8 & 551 & 84.8 & 552 & 85.9 & 1672 & 85.1 & 72.5 \\
\hline Rent & 24 & 3.6 & 20 & 3.1 & 26 & 4.0 & 70 & 3.6 & 24.6 \\
\hline Other & 11 & 1.6 & 10 & 1.5 & 12 & 1.9 & 33 & 1.7 & 2.9 \\
\hline No response & 67 & 10.0 & 69 & 10.6 & 53 & 8.2 & 189 & 9.6 & - \\
\hline \multicolumn{10}{|l|}{ Health Status } \\
\hline Excellent & 127 & 18.9 & 115 & 17.7 & 93 & 14.5 & 335 & 17.1 & 21.2 \\
\hline Very Good & 257 & 38.3 & 244 & 37.5 & 278 & 43.2 & 779 & 39.7 & 37.9 \\
\hline Good & 175 & 26.1 & 169 & 26.0 & 163 & 25.4 & 507 & 25.8 & 28.3 \\
\hline Fair & 45 & 6.7 & 54 & 8.3 & 54 & 8.4 & 153 & 7.8 & 8.9 \\
\hline Poor & 8 & 1.2 & 10 & 1.5 & 8 & 1.2 & 26 & 1.3 & 3.6 \\
\hline No response & 59 & 8.8 & 58 & 8.9 & 47 & 7.3 & 164 & 8.4 & - \\
\hline \multicolumn{10}{|l|}{ Social Values Orientation } \\
\hline Aggressive/Competitive & 27 & 4.0 & 20 & 3.1 & 23 & 3.6 & 70 & 3.6 & - \\
\hline Individualistic & 147 & 21.9 & 141 & 21.7 & 152 & 23.6 & 440 & 22.4 & - \\
\hline Cooperative/Altruistic & 429 & 63.9 & 428 & 65.9 & 414 & 64.4 & 1271 & 64.7 & - \\
\hline Other & 13 & 1.9 & 11 & 1.7 & 10 & 1.6 & 34 & 1.7 & - \\
\hline No response & 55 & 8.2 & 50 & 7.7 & 44 & 6.8 & 149 & 7.6 & - \\
\hline
\end{tabular}


Table 3: Percentage of Respondents Choosing each Policy Option, by assumed IA value $(\epsilon / \gamma)$

\begin{tabular}{|c|c|c|c|c|c|}
\hline Domain & $\epsilon$ or $\gamma$ & Policy A * & $95 \% \mathrm{CI}$ & Policy B $\ddagger$ & $95 \% \mathrm{CI}$ \\
\hline \multirow[t]{5}{*}{ Income } & 1.0 & 72.58 & {$[64,80]$} & 27.42 & {$[20,36]$} \\
\hline & 1.5 & 68.15 & {$[60,76]$} & 31.85 & {$[24,40]$} \\
\hline & 2.0 & 67.65 & {$[59,75]$} & 32.35 & {$[25,41]$} \\
\hline & 2.5 & 52.86 & {$[44,61]$} & 47.14 & {$[39,56]$} \\
\hline & 3.0 & 65.44 & {$[57,73]$} & 34.56 & {$[27,43]$} \\
\hline \multirow[t]{5}{*}{ Health } & 1.0 & 50.82 & {$[42,60]$} & 49.18 & {$[40,58]$} \\
\hline & 1.5 & 49.23 & {$[41,58]$} & 50.77 & {$[42,59]$} \\
\hline & 2.0 & 48.20 & {$[40,57]$} & 51.80 & {$[43,60]$} \\
\hline & 2.5 & 46.67 & {$[38,55]$} & 53.33 & {$[44,62]$} \\
\hline & 3.0 & 47.58 & {$[39,56]$} & 52.42 & {$[43,61]$} \\
\hline \multirow[t]{5}{*}{ Bivariate } & 1.0 & 80.30 & {$[73,86]$} & 19.70 & {$[14,27]$} \\
\hline & 1.5 & 56.45 & {$[47,65]$} & 43.55 & {$[35,52]$} \\
\hline & 2.0 & 43.85 & {$[35,52]$} & 56.15 & {$[47,64]$} \\
\hline & 2.5 & 33.08 & {$[25,42]$} & 66.92 & {$[58,75]$} \\
\hline & 3.0 & 37.01 & {$[29,46]$} & 62.99 & {$[54,71]$} \\
\hline
\end{tabular}

* Policy A: The more equal distribution with a lower mean and lower variance.

$\ddagger$ Policy B: The less equal distribution with a higher mean and higher variance. 
Table 4: Structural Estimates of Mean IA Values for Income, Health and Bivariate Distributions

\begin{tabular}{|c|c|c|c|c|c|c|}
\hline \multirow[b]{2}{*}{ Full Sample } & \multicolumn{2}{|c|}{ Income distribution } & \multicolumn{2}{|c|}{ Health distribution } & \multicolumn{2}{|c|}{ Bivariate distribution } \\
\hline & $\begin{array}{c}\epsilon \\
3.268^{* * *} \\
(0.811) \\
\end{array}$ & $\begin{array}{c}\frac{\ln (\sigma)}{-23.431^{* * *}} \\
(7.719) \\
\end{array}$ & $\begin{array}{c}\epsilon \\
1.174 \\
(0.752) \\
\end{array}$ & $\begin{array}{c}\ln (\sigma) \\
-2.041 \\
(3.82) \\
\end{array}$ & $\begin{array}{c}\gamma \\
1.663^{* * *} \\
(0.075) \\
\end{array}$ & $\begin{array}{c}\ln (\sigma) \\
0.809^{* * *} \\
(0.125) \\
\end{array}$ \\
\hline Split Samples & & & & & & \\
\hline Age $\leq 60$ & $\begin{array}{c}3.164^{* * *} \\
(0.945)\end{array}$ & $\begin{array}{c}-22.965^{* *} \\
(9.001)\end{array}$ & $\begin{array}{l}0.996^{* *} \\
(0.425)\end{array}$ & $\begin{array}{c}-2.38 \\
(2.206)\end{array}$ & $\begin{array}{l}1.86^{* * *} \\
(0.142)\end{array}$ & $\begin{array}{c}0.758^{* * *} \\
(0.192)\end{array}$ \\
\hline Age $>60$ & $\begin{array}{c}3.297^{* *} \\
(1.356)\end{array}$ & $\begin{array}{l}-23.323^{*} \\
(12.911)\end{array}$ & $\begin{array}{c}6.412 \\
(17.396)\end{array}$ & $\begin{array}{l}-22.519 \\
(69.648)\end{array}$ & $\begin{array}{c}1.544^{* * *} \\
(0.084)\end{array}$ & $\begin{array}{c}0.696^{* * *} \\
(0.157)\end{array}$ \\
\hline Females & $\begin{array}{c}3.329^{* *} \\
(1.296)\end{array}$ & $\begin{array}{c}-24.687^{* *} \\
(12.345)\end{array}$ & $\begin{array}{c}1.628^{* * *} \\
(0.539)\end{array}$ & $\begin{array}{c}-4.997^{* *} \\
(2.3)\end{array}$ & $\begin{array}{c}1.729^{* * *} \\
(0.198)\end{array}$ & $\begin{array}{c}0.863^{* * *} \\
(0.31)\end{array}$ \\
\hline Males & $\begin{array}{c}3.225^{* * *} \\
(0.96)\end{array}$ & $\begin{array}{c}-23.029^{* *} \\
(9.141)\end{array}$ & $\begin{array}{c}1.237 \\
(0.952)\end{array}$ & $\begin{array}{l}-2.208 \\
(4.757)\end{array}$ & $\begin{array}{c}1.643^{* * *} \\
(0.078)\end{array}$ & $\begin{array}{c}0.699^{* * *} \\
(0.133)\end{array}$ \\
\hline G./F./P. Health & $\begin{array}{c}3.358^{* * *} \\
(1.148)\end{array}$ & $\begin{array}{c}-24.514^{* *} \\
(10.928)\end{array}$ & $\begin{array}{l}1.888^{*} \\
(1.053)\end{array}$ & $\begin{array}{l}-5.298 \\
(3.987)\end{array}$ & $\begin{array}{c}1.718^{* * *} \\
(0.109)\end{array}$ & $\begin{array}{c}0.565^{* * *} \\
(0.182)\end{array}$ \\
\hline E./VG. Health & $\begin{array}{c}3.142^{* * *} \\
(1.098)\end{array}$ & $\begin{array}{c}-22.206^{* *} \\
(10.451)\end{array}$ & $\begin{array}{c}1.049 \\
(0.817)\end{array}$ & $\begin{array}{l}-1.782 \\
(4.211)\end{array}$ & $\begin{array}{c}1.633^{* * *} \\
(0.096)\end{array}$ & $\begin{array}{c}0.813^{* * *} \\
(0.163)\end{array}$ \\
\hline High Education & $\begin{array}{c}2.949^{* *} \\
(1.219)\end{array}$ & $\begin{array}{c}-20.572^{*} \\
(11.598)\end{array}$ & $\begin{array}{c}4.145 \\
(6.589)\end{array}$ & $\begin{array}{l}-14.189 \\
(25.477)\end{array}$ & $\begin{array}{l}1.61^{* * *} \\
(0.084)\end{array}$ & $\begin{array}{c}0.541^{* * *} \\
(0.15)\end{array}$ \\
\hline Low Education & $\begin{array}{c}3.321^{* * *} \\
(1.000)\end{array}$ & $\begin{array}{c}-23.938^{* *} \\
(9.525)\end{array}$ & $\begin{array}{c}0.581 \\
(0.974)\end{array}$ & $\begin{array}{l}-0.104 \\
(4.891)\end{array}$ & $\begin{array}{c}1.707^{* * *} \\
(0.122)\end{array}$ & $\begin{array}{c}0.881^{* * *} \\
(0.195)\end{array}$ \\
\hline FT employed & $\begin{array}{c}3.262^{* *} \\
(1.613)\end{array}$ & $\begin{array}{l}-22.903 \\
(15.356)\end{array}$ & $\begin{array}{c}1.717^{* * *} \\
(0.432)\end{array}$ & $\begin{array}{c}-5.295^{* * *} \\
(1.752)\end{array}$ & $\begin{array}{c}1.505^{* * *} \\
(0.083)\end{array}$ & $\begin{array}{c}0.688^{* * *} \\
(0.16)\end{array}$ \\
\hline Not FT employed & $\begin{array}{c}3.254^{* * *} \\
(0.873)\end{array}$ & $\begin{array}{c}-23.902^{* * *} \\
(8.318)\end{array}$ & - & - & $\begin{array}{c}1.884^{* * *} \\
(0.133)\end{array}$ & $\begin{array}{c}0.717^{* * *} \\
(0.183)\end{array}$ \\
\hline Income $<75 \mathrm{~K}$ & $\begin{array}{c}3.507^{* * *} \\
(1.002)\end{array}$ & $\begin{array}{c}-26.591^{* * *} \\
(9.556)\end{array}$ & $\begin{array}{c}0.946 \\
(1.241)\end{array}$ & $\begin{array}{l}-1.422 \\
(6.358)\end{array}$ & $\begin{array}{c}1.984^{* * *} \\
(0.18)\end{array}$ & $\begin{array}{c}0.665^{* * *} \\
(0.235)\end{array}$ \\
\hline Income $\geq 75 \mathrm{~K}$ & $\begin{array}{l}2.998^{* *} \\
(1.175)\end{array}$ & $\begin{array}{c}-20.68^{*} \\
(11.187)\end{array}$ & $\begin{array}{c}2.275 \\
(1.578)\end{array}$ & $\begin{array}{l}-6.659 \\
(5.528)\end{array}$ & $\begin{array}{c}1.472^{* * *} \\
(0.081)\end{array}$ & $\begin{array}{c}0.758^{* * *} \\
(0.157)\end{array}$ \\
\hline Coop./Alt. & $\begin{array}{c}3.186^{* * *} \\
(0.798)\end{array}$ & $\begin{array}{c}-22.9^{* * *} \\
(7.594)\end{array}$ & $\begin{array}{l}2.289^{* *} \\
(1.001)\end{array}$ & $\begin{array}{c}-7.087^{* *} \\
(3.503)\end{array}$ & $\begin{array}{c}1.714^{* * *} \\
(0.086)\end{array}$ & $\begin{array}{c}0.639^{* * *} \\
(0.139)\end{array}$ \\
\hline Agg./Comp./Ind./Other & $\begin{array}{c}3.518 \\
(2.656)\end{array}$ & $\begin{array}{l}-25.138 \\
(25.295)\end{array}$ & - & - & $\begin{array}{c}1.532^{* * *} \\
(0.152)\end{array}$ & $\begin{array}{c}1.153^{* * *} \\
(0.274)\end{array}$ \\
\hline
\end{tabular}

Notes: G./F./P. health denotes good/fair/poor self-assessed health status. E./VG. denotes excellent/very good selfassessed health status. Low Education denotes less than university education; High Education denotes university graduate. Coop./Alt. denotes cooperative-altruistic value orientations; Agg./Comp./Ind./Other denotes aggressive, competitive, individualistic or other social value orientations. Missing values in the table denote that the model did not converge for that estimation sample. 
Table 5: Mean IA values for health distribution from latent class structural estimation

\begin{tabular}{|c|c|c|}
\hline \multirow[b]{3}{*}{ Preference equations } & \multicolumn{2}{|c|}{ Health distribution } \\
\hline & Class 1 & Class 2 \\
\hline & & \\
\hline$\epsilon$ & $\begin{array}{l}7.304^{* *} \\
(3.511)\end{array}$ & $\begin{array}{c}0.339 \\
(0.418)\end{array}$ \\
\hline $\ln (\sigma)$ & $\begin{array}{c}-2.402^{* *} \\
(0.941)\end{array}$ & $\begin{array}{c}-4.280^{* * *} \\
(0.438)\end{array}$ \\
\hline \multicolumn{3}{|l|}{ Class membership } \\
\hline Age $>60$ & $\begin{array}{l}-0.060 \\
(0.071)\end{array}$ & - \\
\hline Male & $\begin{array}{l}-0.018 \\
(0.039)\end{array}$ & - \\
\hline E./VG. health & $\begin{array}{c}0.017 \\
(0.030)\end{array}$ & - \\
\hline FT employed & $\begin{array}{c}0.020 \\
(0.052)\end{array}$ & - \\
\hline Coop./Alt. & $\begin{array}{l}-0.053 \\
(0.071)\end{array}$ & - \\
\hline Constant & $\begin{array}{c}0.036 \\
(0.280)\end{array}$ & - \\
\hline Class share & 0.493 & 0.507 \\
\hline \# subjects & & \\
\hline
\end{tabular}

Notes: E./VG. denotes excellent/very good self-assessed health status. Coop./Alt. denotes cooperative-altruistic value orientations. Bootstrapped standard errors with 250 repetitions. 
Table 6: Illustrative Statements Regarding Predominant Participant Reasoning

\begin{tabular}{|c|c|c|c|}
\hline Rationale & Income 1 & Health & Bivariate \\
\hline \multicolumn{4}{|c|}{ More-averse participants who chose the more-equal distribution } \\
\hline $\begin{array}{l}\text { Concern } \\
\text { for In- } \\
\text { equality }\end{array}$ & $\begin{array}{l}\text { "Basic fairness. Policy B } \\
\text { increases the average in- } \\
\text { come of the country but } \\
\text { widens the gap between } \\
\text { poor and rich, and is ba- } \\
\text { sically a gift to the Inc5 } \\
\text { group." }\end{array}$ & $\begin{array}{l}\text { "There is more equity in } \\
\text { that the difference in ex- } \\
\text { pectancies is closer for } \\
\text { Policy A. It is more just } \\
\text { to all." }\end{array}$ & $\begin{array}{l}\text { "I chose policy A because } \\
\text { I think it is better to have } \\
\text { equity in a country even if } \\
\text { it means the level of health } \\
\text { obtained is lower overall." }\end{array}$ \\
\hline $\begin{array}{l}\text { Concern } \\
\text { for Worst- } \\
\text { off }\end{array}$ & $\begin{array}{l}\text { "I felt it was more im- } \\
\text { portant to help the poorer } \\
\text { two income levels than the } \\
\text { richer two levels even if it } \\
\text { meant that the average in- } \\
\text { come would go down." }\end{array}$ & $\begin{array}{l}\text { "I believe in fairness. We } \\
\text { should be judged by how } \\
\text { we treat the least fortu- } \\
\text { nate among us. I believe } \\
\text { it best to increase the min- } \\
\text { imum life expectancy or } \\
\text { health level so that the } \\
\text { least healthy will have an } \\
\text { increased life expectancy." }\end{array}$ & $\begin{array}{l}\text { "Promotes health for } \\
\text { lower income people and } \\
\text { therefore the greater } \\
\text { good. Because those in } \\
\text { the lower two income cat- } \\
\text { egories are better served } \\
\text { by Policy A." }\end{array}$ \\
\hline \multicolumn{4}{|c|}{ Less-averse participants who chose the less-equal distribution } \\
\hline $\begin{array}{l}\text { Opportunity } \\
\text { for Higher } \\
\text { Outcome }\end{array}$ & $\begin{array}{l}\text { "Inc5 has the ability to } \\
\text { earn more income. In a } \\
\text { free democratic society we } \\
\text { all should have the oppor- } \\
\text { tunity to earn as much as } \\
\text { possible." }\end{array}$ & $\begin{array}{l}\text { "Greater opportunity for } \\
\text { living healthy above av- } \\
\text { erage Policy B would } \\
\text { give individuals a longer } \\
\text { health-adjusted life ex- } \\
\text { pectancy while offering } \\
\text { the same level of access to } \\
\text { healthcare as in policy A." }\end{array}$ & $\begin{array}{l}\text { "Good health, leading to } \\
\text { a longer life is in of itself } \\
\text { a form of wealth. Live } \\
\text { longer and heatlhier. We } \\
\text { all want to live a long life." }\end{array}$ \\
\hline $\begin{array}{l}\text { Higher } \\
\text { Mean }\end{array}$ & $\begin{array}{l}\text { "Higher average income } \\
\text { and this is good for the } \\
\text { economy/society." }\end{array}$ & $\begin{array}{l}\text { "I chose B since the aver- } \\
\text { age health of the country } \\
\text { will be higher at the end } \\
\text { of the } 5 \text { yr term than with } \\
\text { policy A, but in the long } \\
\text { term, the benefits are best } \\
\text { with policy B." }\end{array}$ & $\begin{array}{l}\text { "The average life- } \\
\text { expectancy is higher, } \\
\text { taking into account all } \\
\text { income brackets, so it } \\
\text { is fair. I believe in the } \\
\text { utilitarian principle which } \\
\text { suggests that the higher } \\
\text { benefit given to the ma- } \\
\text { jority is the preferred } \\
\text { option." }\end{array}$ \\
\hline
\end{tabular}


Appendix A. 


\section{McMaster Economics Inequality Survey V1}

Thank you for agreeing to complete this survey.

There are 50 questions in this survey

\section{Introduction}

Thank you for participating in our survey.

As a gesture of our appreciation, you will be entered into a draw for one of the $\$ 250$ prizes when you complete the survey. To be eligible, please re-enter the ID Code provided to you in your letter into the space below.

Please write your answer here:

This survey contains five sections: in sections 1 - 3 we ask you some questions regarding inequality. Section 4 asks you questions about dividing money; and section 5 asks you some questions about your background, which are used for statistical purposes only. We anticipate that the survey will take 10-15 minutes to complete.

Each of sections 1 - 3 presents a scenario relating to government policies in a hypothetical country. In each case, we provide you with some basic information regarding the effects of each policy and ask which policy you would prefer to be implemented. There are no right or wrong answers to these questions. Your answers depend on your personal judgment; we ask only that you reflect carefully on your choices.

Remember, when you complete the survey, you will be entered into the draw for the $\$ 250$ prizes, so we'd really like you to complete the whole survey. Thanks! 


\section{Section 1 of 5: Income Inequality}

Imagine a hypothetical country in which citizens are identical in all ways except one: their incomes. The government must choose between implementing one of two policies. Both policies will have an impact on citizens' incomes. Indeed, the only impact of the policies is on the level and distribution of income within the population, though each policy affects the incomes of different groups differently. These impacts will not happen instantaneously, but will occur over the next 3-5 years.

The table below presents information for each policy on the resulting yearly income for individuals in the country, after taking into account all taxes and government programs. (We present the same information in a graph below the table). In this country there are five levels of income, and the number of people with each income level is identical. In the table we label the income groups Inc1-Inc5, where Inc1 refers to the group with the lowest level of income and Inc5 refers to the group with highest level of income. Everyone within each income group has the same income, but incomes differ across the five groups.

The government must choose between the two policies listed. We ask you which of the two policies you would prefer that the government implement.

There is no right or wrong answer; we are interested in your personal judgment.

Question 1: Annual Income, by Income Group, under each of Policy A and Policy B

\begin{tabular}{|l|c|c|c|c|c|c|}
\hline $\begin{array}{l}\text { Income Groups } \\
\text { (each group } \\
\text { contains the same } \\
\text { number of } \\
\text { individuals) }\end{array}$ & Inc1 & Inc2 & Inc3 & Inc4 & Inc5 & $\begin{array}{c}\text { Average Income in } \\
\text { the Country }\end{array}$ \\
\hline Policy A & $\$ 14,600$ & $\$ 32,700$ & $\$ 49,700$ & $\$ 73,500$ & $\$ 135,500$ & $\$ 61,200$ \\
\hline Policy B & $\$ 12,200$ & $\$ 30,700$ & $\$ 49,700$ & $\$ 75,500$ & $\$ 168,500$ & $\$ 67,320$ \\
\hline
\end{tabular}




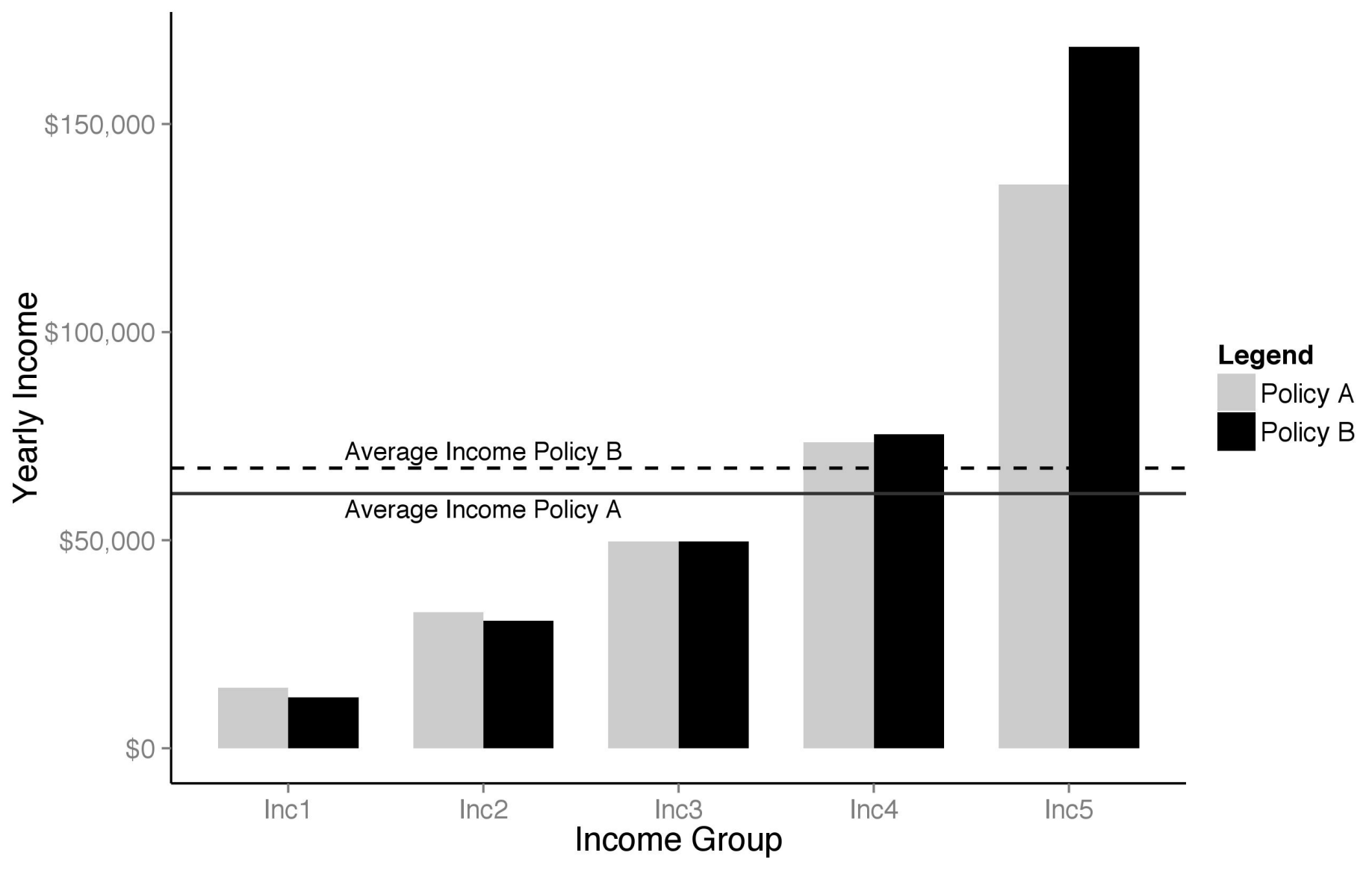

The government will implement either Policy A or Policy B. Please indicate which policy you prefer that the government implement.

Please choose only one of the following:

Policy A

Policy B

Why did you choose this policy? (Please write response in box below)

Please write your answer here: 


\section{Section 2 of 5: Health Inequality}

Imagine a hypothetical country in which citizens are identical in all ways except one: their levels of health. The government must choose between implementing one of two policies. Both policies will have an impact on citizens' health. Indeed, the only impact of both policies is on the level and distribution of health within the population, though each policy affects the health of different groups differently. Note that citizens' access to health care will be the same under both policies. These impacts will not happen instantaneously, but will occur over the next 3-5 years.

The table below presents information for each policy on the resulting levels of people's health, where health is measured by health-adjusted life expectancy. (We present the same information in a graph below the table). This measure of health combines information on both how many years a person can expect to live and how healthy those years will be. For example, two people might both expect to live to $\mathbf{7 5}$ years. If one person lives in full health until they die suddenly of a heart attack, then their health-adjusted life expectancy would be $\mathbf{7 5}$ years. If the second person, however, lives the last ten years of their life with a painful chronic condition, this individual's health-adjusted life expectancy is less than 75 years (e.g., 71 years) because they suffer from the chronic condition.

In this country there are five levels of health, and the number of people with each health level is identical. In the table we label the health groups H1-H5, where H1 refers to the group with the shortest health-adjusted life expectancy and $\mathrm{H} 5$ refers to the group with the longest health-adjusted life expectancy. Everyone within each group has the same health-adjusted life expectancy, but healthadjusted life expectancies differ across the five groups. To place the impact of the policies in context, average life expectancy for both Canada and the US has increased by about 1 year every decade since 1950.

The government must choose between the two policies listed. We ask you which of the two policies you would prefer that the government implement.

There is no right or wrong answer; we are interested in your personal judgment.

Queston 2: Health-adjusted life expectancy (measured in years), by Level of Health under Policies A and $B$

\begin{tabular}{|l|c|c|c|c|c|c|}
\hline $\begin{array}{l}\text { Health Groups } \\
\text { (each group contains } \\
\text { the same number of } \\
\text { individuals) }\end{array}$ & $\mathrm{H} 1$ & $\mathrm{H} 2$ & $\mathrm{H3}$ & $\mathrm{H} 4$ & $\mathrm{H5}$ & $\begin{array}{c}\text { Average Level of Health } \\
\text { in the Country }\end{array}$ \\
\hline Policy A & 63.0 & 67.0 & 70.0 & 73.0 & 77.0 & 70.0 \\
\hline Policy B & 55.0 & 64.5 & 70.0 & 76.0 & 88.0 & 70.7 \\
\hline
\end{tabular}




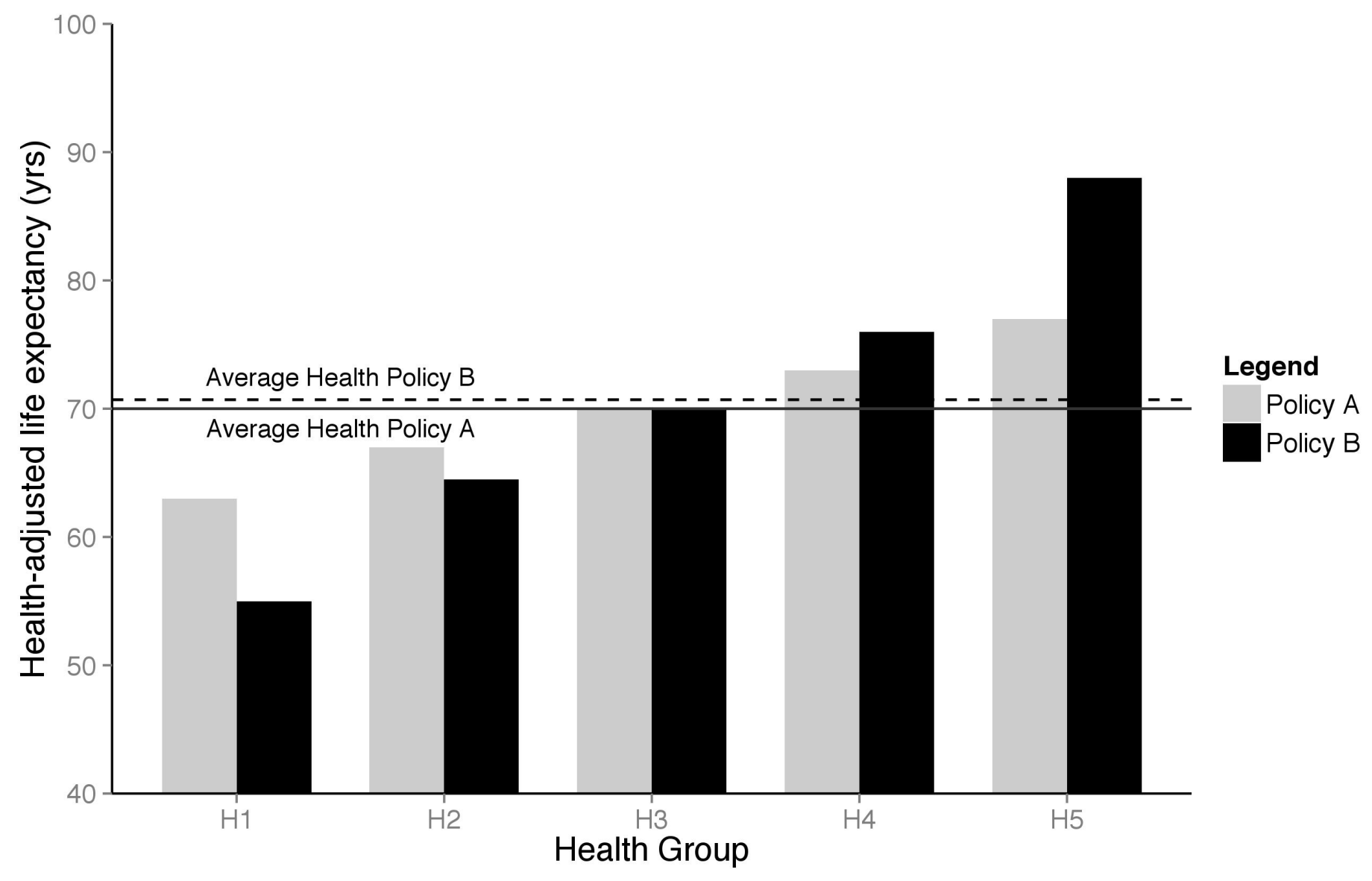

The government will implement either Policy A or Policy B. Please indicate which policy you prefer that the government implement.

Please choose only one of the following:

Policy A

Policy B

Why did you choose this policy? (Please write response in box below)

Please write your answer here: 


\section{Section 3 of 5: Income-Related Health Inequality}

Imagine a hypothetical country in which citizens are identical in all ways except two: their incomes and their health. The government must choose between implementing one of two policies. Both policies will have no impact on people's income, but will have an impact on the level and distribution of people's health. Further, this impact on health is the only impact of the policies, and the health impact depends on a person's income. Note that citizens' access to health care will be the same under both policies. These impacts will not happen instantaneously, but will occur over the next 3-5 years.

For each policy, the table below presents information, by income level, on the resulting levels of health for those with the indicated income. As in the earlier section, income is measured by annual income, after taking into account all taxes and government programs. There are five income groups in this country (Inc1 - Inc5), each income group contains the same number of people and everyone within each group has the same income but incomes differ across the five groups as indicated in the table. Similarly, as in the earlier section, health is measured by health-adjusted life expectancy. For each income group, the table provides information on people's health-adjusted life expectancy under each of the two proposed policies. Within each income group everyone has the same health-adjusted life expectancy, but the health-adjusted life expectancy differs across the income groups. Again, to place the impact of the policies in context, average life expectancy for both Canada and the US has increased by about 1 year every decade since 1950.

The government must choose between the two policies listed. We ask you which of the two policies you would prefer that the government implement.

There is no right or wrong answer; we are interested in your personal judgment.

Question 3: Health-adjusted life expectancy (in years), by Income level, under Policies A and B

\begin{tabular}{|l|c|c|c|c|c|c|}
\hline $\begin{array}{l}\text { Income Group } \\
\text { (each group } \\
\text { contains the same } \\
\text { number of } \\
\text { individuals) }\end{array}$ & Inc1 & Inc2 & Inc3 & Inc4 & Inc5 & $\begin{array}{c}\text { Average Level of } \\
\text { Health in the Country }\end{array}$ \\
\hline Income-level & $\$ 14,600$ & $\$ 32,700$ & $\$ 49,700$ & $\$ 73,500$ & $\$ 135,500$ & \\
\hline Policy A & 64.0 & 67.0 & 70.0 & 73.0 & 76.0 & 70.0 \\
\hline Policy B & 63.0 & 67.0 & 70.0 & 80.0 & 86.0 & 73.2 \\
\hline
\end{tabular}




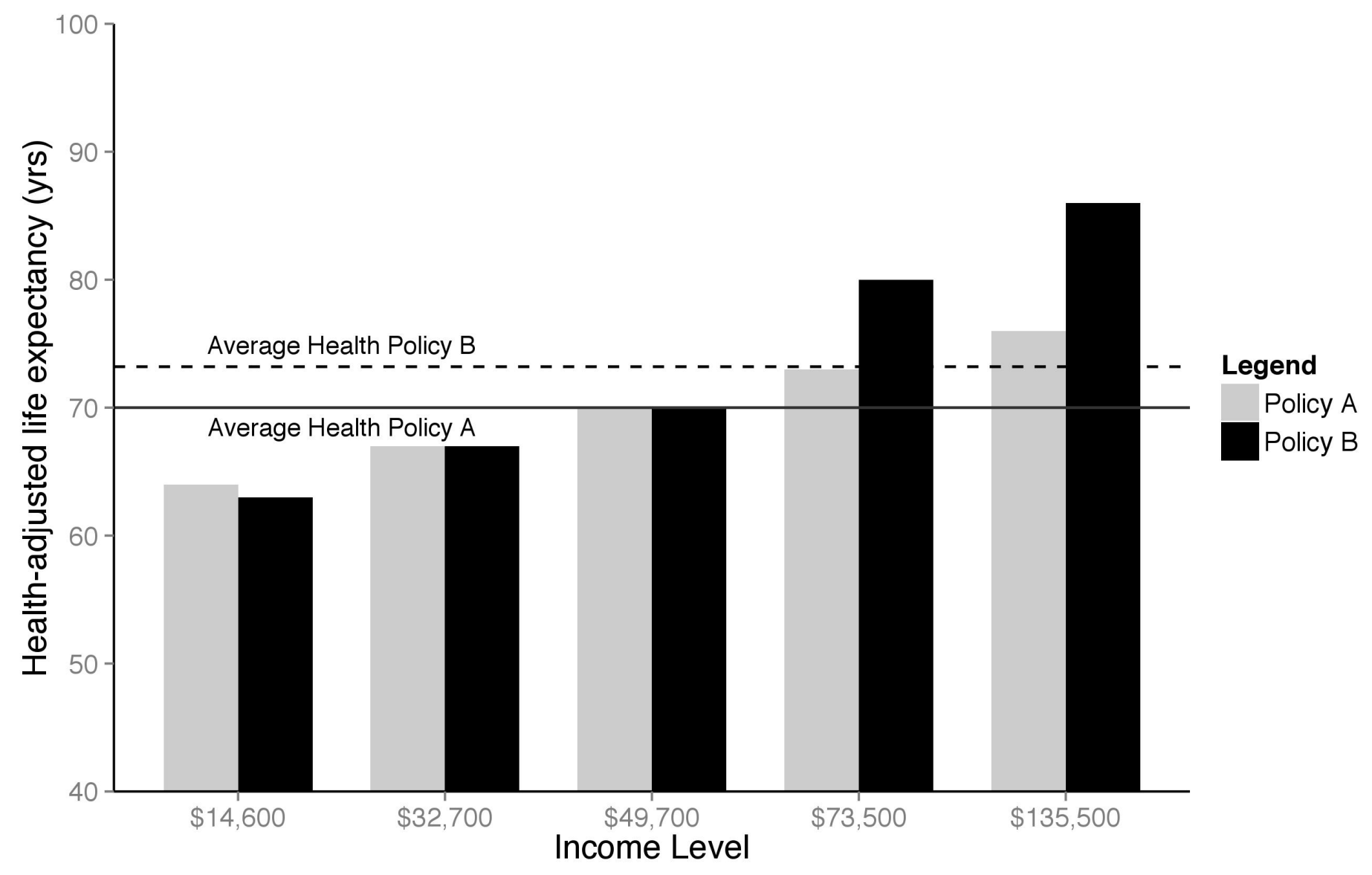

The government will implement either Policy A or Policy B. Please indicate which policy you prefer that the government implement.

Please choose only one of the following:

Policy A

Policy B

Why did you choose this policy? (Please write response in box below)

Please write your answer here: 


\section{Section 4 of 5: Money Sharing}

In this section, we present some hypothetical choices about money sharing. Your choices affect the amount of money you would receive as well as the amount of money that would be received by a random person with whom you have been matched. You do not know who this other person is.

For each question we present two options and ask you to choose one. Each option describes an amount of money that you would get as well as the amount of money the other person would get.

For some options, you, the other person, or both lose money. These are indicated by negative signs (i.e. $\mathbf{\$ 5 . 0 0}$ means a loss of $\$ 5.00)$. All amounts are in Canadian dollars.

Imagine that at the same time you are making your choices the other person (to whom you have been matched) is answering the same questions, making choices as to how they would split money between themselves and you.

After you have made all of your choices, the final amount of money you would hypothetically "receive" is the total of all amounts that you get from your choices plus the total of all amounts that you get from the other person's choices. Similarly, the final amount the other person would receive is the total of the amounts that you decided to give them through your choices plus the amounts that they decided to give themselves through their choices.

To help you understand, we provide an example on the next screen.

\section{Example}

Here is an example of the kind of decision you will be asked to make. Two options will appear on your computer screen.

\begin{tabular}{|c|c|c|c|}
\hline \multicolumn{2}{|c|}{ Option A } & \multicolumn{2}{|c|}{ Option B } \\
\hline You Receive & Other Receives & You Receive & Other Receives \\
\hline $\mathbf{\$ 9 . 7 0}$ & $\mathbf{- \$ 2 . 6 0}$ & $\mathbf{\$ 1 0 . 0 0}$ & $\mathbf{\$ 0 . 0 0}$ \\
\hline
\end{tabular}

You must select either Option A or Option B.

O: Option A

O: Option B

\section{Explanation:}

If you choose Option $A$, you would receive $\$ 9.70$ and the other person would lose $\$ 2.60$.

If you choose Option $B$, you would receive $\$ 10.00$ and the other person would receive nothing.

We now present 24 scenarios like this example. 
There are no right or wrong answers; we are interested in your personal judgment.

Scenario 1 of 24

\begin{tabular}{|c|c|c|c|}
\hline \multicolumn{2}{|c|}{ Option A } & \multicolumn{2}{|c|}{ Option B } \\
\hline You Receive & Other Receives & You Receive & Other Receives \\
\hline \hline$\$ 7.10$ & $\$ 7.10$ & $\$ 5.00$ & $\$ 8.70$ \\
\hline
\end{tabular}

Please choose only one of the following:

Option A

Option B

\section{Scenario 2 of 24}

\begin{tabular}{|c|c|c|c|}
\hline \multicolumn{2}{|c|}{ Option A } & \multicolumn{2}{|c|}{ Option B } \\
\hline You Receive & Other Receives & You Receive & Other Receives \\
\hline$-\$ 8.70$ & $-\$ 5.00$ & $-\$ 7.10$ & $-\$ 7.10$ \\
\hline
\end{tabular}

Please choose only one of the following:

Option A

Option B

\section{Scenario 3 of 24}

\begin{tabular}{|c|c|c|c|}
\hline \multicolumn{2}{|c|}{ Option A } & \multicolumn{2}{|c|}{ Option B } \\
\hline You Receive & Other Receives & You Receive & Other Receives \\
\hline$-\$ 8.70$ & $\$ 5.00$ & $-\$ 9.70$ & $\$ 2.60$ \\
\hline
\end{tabular}

Please choose only one of the following:

Option A

Option B

\section{Scenario 4 of 24}

\begin{tabular}{|c|c|c|c|}
\hline \multicolumn{2}{|c|}{ Option A } & \multicolumn{2}{|c|}{ Option B } \\
\hline You Receive & Other Receives & You Receive & Other Receives \\
\hline$\$ 0.00$ & $-\$ 10.00$ & $\$ 2.60$ & $-\$ 9.70$ \\
\hline
\end{tabular}

Please choose only one of the following:

Option A

Option B 


\section{Scenario 5 of 24}

\begin{tabular}{|c|c|c|c|}
\hline \multicolumn{2}{|c|}{ Option A } & \multicolumn{2}{|c|}{ Option B } \\
\hline You Receive & Other Receives & You Receive & Other Receives \\
\hline$-\$ 7.10$ & $\$ 7.10$ & $-\$ 8.70$ & $\$ 5.00$ \\
\hline
\end{tabular}

Please choose only one of the following:

Option A

Option B

\section{Scenario 6 of 24}

\begin{tabular}{|c|c|c|c|}
\hline \multicolumn{2}{|c|}{ Option A } & \multicolumn{2}{|c|}{ Option B } \\
\hline You Receive & Other Receives & You Receive & Other Receives \\
\hline$\$ 9.70$ & $-\$ 2.60$ & $\$ 10.00$ & $\$ 0.00$ \\
\hline
\end{tabular}

Please choose only one of the following:

Option A

Option B

\section{Scenario 7 of 24}

\begin{tabular}{|c|c|c|c|}
\hline \multicolumn{2}{|c|}{ Option A } & \multicolumn{2}{|c|}{ Option B } \\
\hline You Receive & Other Receives & You Receive & Other Receives \\
\hline$-\$ 2.60$ & $-\$ 9.70$ & $\$ 0.00$ & $-\$ 10.00$ \\
\hline
\end{tabular}

Please choose only one of the following:

Option A

Option B

\section{Scenario 8 of 24}

\begin{tabular}{|c|c|c|c|}
\hline \multicolumn{2}{|c|}{ Option A } & \multicolumn{2}{|c|}{ Option B } \\
\hline You Receive & Other Receives & You Receive & Other Receives \\
\hline$-\$ 9.70$ & $\$ 2.60$ & $-\$ 10.00$ & $\$ 0.00$ \\
\hline
\end{tabular}

Please choose only one of the following:

Option A

Option B

\section{Scenario 9 of 24}

\begin{tabular}{|c|c|c|c|}
\hline \multicolumn{2}{|c|}{ Option A } & \multicolumn{2}{|c|}{ Option B } \\
\hline You Receive & Other Receives & You Receive & Other Receives \\
\hline$-\$ 2.60$ & $\$ 9.70$ & $-\$ 5.00$ & $\$ 8.70$ \\
\hline
\end{tabular}


Please choose only one of the following:

Option A

Option B

\section{Scenario 10 of 24}

\begin{tabular}{|c|c|c|c|}
\hline \multicolumn{2}{|c|}{ Option A } & \multicolumn{2}{|c|}{ Option B } \\
\hline You Receive & Other Receives & You Receive & Other Receives \\
\hline$\$ 10.00$ & $\$ 0.00$ & $\$ 9.70$ & $\$ 2.60$ \\
\hline
\end{tabular}

Please choose only one of the following:

Option A

Option B

\section{Scenario 11 of 24}

\begin{tabular}{|c|c|c|c|}
\hline \multicolumn{2}{|c|}{ Option A } & \multicolumn{2}{|c|}{ Option B } \\
\hline You Receive & Other Receives & You Receive & Other Receives \\
\hline$\$ 9.70$ & $\$ 2.60$ & $\$ 8.70$ & $\$ 5.00$ \\
\hline
\end{tabular}

Please choose only one of the following:

Option A

Option B

\section{Scenario 12 of 24}

\begin{tabular}{|c|c|c|}
\hline \multicolumn{2}{|c|}{ Option A } & \multicolumn{2}{|c|}{ Option B } \\
\hline You Receive & Other Receives \\
\hline$\$ 8.70$ & You Receive & Other Receives \\
\hline & $-\$ 5.00$ & $\$ 9.70$ \\
\hline
\end{tabular}

Please choose only one of the following:

Option A

Option B

\section{Scenario 13 of 24}

\begin{tabular}{|c|c|c|c|}
\hline \multicolumn{2}{|c|}{ Option A } & \multicolumn{2}{|c|}{ Option B } \\
\hline You Receive & Other Receives & You Receive & Other Receives \\
\hline$\$ 5.00$ & $-\$ 8.70$ & $\$ 7.10$ & $-\$ 7.10$ \\
\hline
\end{tabular}

Please choose only one of the following:

Option A

Option B

\section{Scenario 14 of 24}




\begin{tabular}{|c|c|c|c|}
\hline \multicolumn{2}{|c|}{ Option A } & \multicolumn{2}{|c|}{ Option B } \\
\hline You Receive & Other Receives & You Receive & Other Receives \\
\hline$-\$ 7.10$ & $-\$ 7.10$ & $-\$ 5.00$ & $-\$ 8.70$ \\
\hline
\end{tabular}

Please choose only one of the following:

Option A

Option B

\section{Scenario 15 of 24}

\begin{tabular}{|c|c|c|c|}
\hline \multicolumn{2}{|c|}{ Option A } & \multicolumn{2}{|c|}{ Option B } \\
\hline You Receive & Other Receives & You Receive & Other Receives \\
\hline$\$ 2.60$ & $\$ 9.70$ & $\$ 0.00$ & $\$ 10.00$ \\
\hline
\end{tabular}

Please choose only one of the following:

Option A

Option B

\section{Scenario 16 of 24}

\begin{tabular}{|c|c|c|c|}
\hline \multicolumn{2}{|c|}{ Option A } & \multicolumn{2}{|c|}{ Option B } \\
\hline You Receive & Other Receives & You Receive & Other Receives \\
\hline$-\$ 9.70$ & $-\$ 2.60$ & $-\$ 8.70$ & $-\$ 5.00$ \\
\hline
\end{tabular}

Please choose only one of the following:

Option A

Option B

\section{Scenario 17 of 24}

\begin{tabular}{|c|c|c|c|}
\hline \multicolumn{2}{|c|}{ Option A } & \multicolumn{2}{|c|}{ Option B } \\
\hline You Receive & Other Receives & You Receive & Other Receives \\
\hline$\$ 8.70$ & $\$ 5.00$ & $\$ 7.10$ & $\$ 7.10$ \\
\hline
\end{tabular}

Please choose only one of the following:

Option A

Option B

\section{Scenario 18 of 24}

\begin{tabular}{|c|c|c|c|}
\hline \multicolumn{2}{|c|}{ Option A } & \multicolumn{2}{|c|}{ Option B } \\
\hline You Receive & Other Receives & You Receive & Other Receives \\
\hline$\$ 0.00$ & $\$ 10.00$ & $-\$ 2.60$ & $\$ 9.70$ \\
\hline
\end{tabular}

Please choose only one of the following: 
Option A

Option B

\section{Scenario 19 of 24}

\begin{tabular}{|c|c|c|c|}
\hline \multicolumn{2}{|c|}{ Option A } & \multicolumn{2}{|c|}{ Option B } \\
\hline You Receive & Other Receives & You Receive & Other Receives \\
\hline$\$ 7.10$ & $-\$ 7.10$ & $\$ 8.70$ & $-\$ 5.00$ \\
\hline
\end{tabular}

Please choose only one of the following:

Option A

Option B

\section{Scenario $\mathbf{2 0}$ of $\mathbf{2 4}$}

\begin{tabular}{|c|c|c|c|}
\hline \multicolumn{2}{|c|}{ Option A } & \multicolumn{2}{|c|}{ Option B } \\
\hline You Receive & Other Receives & You Receive & Other Receives \\
\hline$-\$ 5.00$ & $-\$ 8.70$ & $-\$ 2.60$ & $-\$ 9.70$ \\
\hline
\end{tabular}

Please choose only one of the following:

Option A

Option B

\section{Scenario 21 of 24}

\begin{tabular}{|c|c|c|c|}
\hline \multicolumn{2}{|c|}{ Option A } & \multicolumn{2}{|c|}{ Option B } \\
\hline You Receive & Other Receives & You Receive & Other Receives \\
\hline$\$ 2.60$ & $-\$ 9.70$ & $\$ 5.00$ & $-\$ 8.70$ \\
\hline
\end{tabular}

Please choose only one of the following:

Option A

Option B

\section{Scenario 22 of 24}

\begin{tabular}{|c|c|c|c|}
\hline \multicolumn{2}{|c|}{ Option A } & \multicolumn{2}{|c|}{ Option B } \\
\hline You Receive & Other Receives & You Receive & Other Receives \\
\hline$\$ 5.00$ & $\$ 8.70$ & $\$ 2.60$ & $\$ 9.70$ \\
\hline
\end{tabular}

Please choose only one of the following:

Option A

Option B

\section{Scenario 23 of 24}

\begin{tabular}{|c|l|}
\hline Option A & Option B \\
\hline
\end{tabular}




\begin{tabular}{|c|c|c|c|}
\hline You Receive & Other Receives \\
\hline$-\$ 5.00$ & You Receive & Other Receives \\
\hline$\$ 8.70$ & $-\$ 7.10$ & $\$ 7.10$ \\
\hline
\end{tabular}

Please choose only one of the following:

Option A

Option B

\section{Scenario 24 of 24}

\begin{tabular}{|c|c|c|}
\hline \multicolumn{2}{|c|}{ Option A } & \multicolumn{2}{|c|}{ Option B } \\
\hline You Receive & Other Receives \\
\hline$-\$ 10.00$ & You Receive & Other Receives \\
\hline \$0.00 & $-\$ 9.70$ \\
\hline
\end{tabular}

Please choose only one of the following:

Option A

Option B 


\section{Section 5 of 5: Background Information}

This is the last section in the survey. We'd like to collect a bit of background information that we will use for statistical purposes.

\section{What is your sex? *}

Please choose only one of the following:

Female

Male

Prefer not to respond

\section{What is your year of birth?}

Only numbers may be entered in this field. Please check the format of your answer.

Please write your answer here:

(Enter 4 digits, like 1970 or 1956)

In general would you say your health is (excellent, very good, good, fair, poor)? *

Please choose only one of the following:

Excellent

Very Good

Good

Fair

Poor

Prefer not to respond

\section{What is your marital status? *}

Please choose only one of the following:

Single (never married)

Married or Common-Law

Divorced

Widowed

Prefer not to respond

\section{What is your current work status? *}

Please choose only one of the following:

Full-time employment

\section{Part-time employment}

Not employed 


\section{Retired}

Prefer not to respond

\section{Do you own or rent your house / apartment? *}

Please choose only one of the following:

Own

Rent

Other

Prefer not to respond

What is the highest level of education you have attained? *

Please choose only one of the following:

Less than secondary school

Secondary school graduate

Post-secondary graduate (i.e., college, apprentice, trade diploma or certificate)

University graduate

Prefer not to respond

What is your best estimate of the total income (before taxes and deductions) of all household members from all sources in the past 12 months? *

Please choose only one of the following:

No Income

Less than $\$ 20,000$

$\$ 20,000$ to $\$ 49,999$

- $\$ 50,000$ to $\$ 74,999$

( $\$ 75,000$ to $\$ 100,000$

More than $\$ 100,000$

Prefer not to respond

We ask for your income for statistical purposes only and will never release it to anyone.

Have you ever worked in the health care sector? *

Please choose only one of the following:

Yes

No

Prefer not to answer

That's all the questions we have. When you click the button below, your reponse will be recorded and you will automatically be entered into the draw for one of the $\mathbf{\$ 2 5 0}$ prizes. We will contact the winners and we will also post the winning ID Codes on our website.

If you have any additional thoughts or suggestions about our study, please feel free to note them here.

Thanks again for completing our survey and helping us with our research. 
Please write your answer here: 
01.06.2015-08:52

Submit your survey.

Thank you for completing this survey. 


\section{Appendix B.}

\section{Modeling the inequality aversion parameter directly}

Modeling IA through a structural model channels individual preferences elicitation through the assumed functional form of the constructed distributions. On the other hand, directly modeling the inequality aversion parameter itself minimizes the need for such a-priori assumptions on the functional form of the parameter or individual's utility function in the econometric model. We note, however, that the effect of the underlying CRRA cannot be escaped as its functional form is inherently represented through the resulting distributions for the varying IA parameters. Nevertheless, comparisons between the two approaches provides insight on their convergence proprieties and the extent that structure imposed within the utility-consistent approach potentially distorts mean IA estimates.

For individual $i$ we specify inequality aversion as a random parameter with a linear additive index function

$$
I A_{i}=\beta+u_{i}
$$

where $\beta$ is constant and $u_{i} \sim \Lambda\left(0, \frac{s^{2} \pi^{2}}{3}\right)$ is an error term ${ }^{10}$ and dichotomizing responses to a Yes/No format (i.e. Yes if Policy A has been chosen and No if Policy $\mathrm{B}$ has been chosen), an individual would respond Yes if their $I A_{i}$ value was greater than the inequality aversion parameter used in the construction of the presented pair of distributions, $\epsilon_{i}$

$$
\begin{aligned}
P\left(\text { Yes }_{i}\right) & =P\left(I A_{i}>\epsilon_{i}\right)= \\
& =P\left(\beta+u_{i}>\epsilon_{i}\right) \\
& =P\left(\frac{\beta-\epsilon_{i}}{\sigma}>k_{i}\right) \\
& =\Lambda\left(\frac{\beta}{\sigma}-\frac{1}{\sigma} \epsilon_{i}\right)
\end{aligned}
$$

where $k_{j} \sim \Lambda\left(0, \frac{\pi^{2}}{3}\right)$ and $\Lambda($.$) is the standard logistic distribution. For this logit$ model, $\frac{\beta}{\sigma}$ and $\frac{1}{\sigma}$ are estimable parameters with the former estimated as the model constant and the latter as the coefficient of $\epsilon_{i}$. Note that adding covariates in the $I A$ function is trivial.

\footnotetext{
${ }^{10}$ Logistic distribution is chosen for convenience and consistency with the structural model but any symmetric, IID distribution can be used.
} 
Mean IA can be calculated by taking the expectation of eq. (B.1) with respect to $u_{i}$

$$
E\left(I A_{i} \mid \beta\right)=\beta
$$

However, given that we do not observe $\beta$ but only its scaled counterpart, a consistent estimate of mean $I A$ following maximum likelihood estimation is

$$
E\left(I A_{i} \mid \beta\right)=\frac{\left(\frac{\hat{\beta}}{\sigma}\right)}{\left(\frac{\hat{1}}{\sigma}\right)}
$$


Table B1: Mean IA values for income, health and bivariate distributions from direct estimation of the IA parameter

\begin{tabular}{|c|c|c|c|}
\hline All & $\begin{array}{c}\epsilon \text { of Income } \\
\text { distribution }\end{array}$ & $\begin{array}{c}\epsilon \text { of Health } \\
\text { distribution }\end{array}$ & $\begin{array}{c}\gamma \text { of Bivariate } \\
\text { distribution }\end{array}$ \\
\hline Age $\leq 60$ & $\begin{array}{c}3.195^{* * *} \\
(0.38)\end{array}$ & $\begin{array}{c}0.812 \\
(1.162)\end{array}$ & $\begin{array}{l}2.22^{* * *} \\
(0.129)\end{array}$ \\
\hline Age $>60$ & $\begin{array}{c}8.776 \\
(13.247)\end{array}$ & $\begin{array}{c}3.864 \\
(4.847)\end{array}$ & $\begin{array}{c}1.839^{* * *} \\
(0.113)\end{array}$ \\
\hline Females & $\begin{array}{c}4.103^{* * *} \\
(1.372)\end{array}$ & $\begin{array}{c}1.866^{* * *} \\
(0.573)\end{array}$ & $\begin{array}{c}2.082^{* * *} \\
(0.245)\end{array}$ \\
\hline Males & $\begin{array}{l}3.84^{* * *} \\
(0.796)\end{array}$ & $\begin{array}{c}1.40 \\
(1.566)\end{array}$ & $\begin{array}{l}1.98^{* * *} \\
(0.091)\end{array}$ \\
\hline G./F./P. health & $\begin{array}{c}6.504 \\
(4.541)\end{array}$ & $\begin{array}{c}2.121^{* * *} \\
(0.796)\end{array}$ & $\begin{array}{c}2.058^{* * *} \\
(0.122)\end{array}$ \\
\hline E./VG. health & $\begin{array}{c}3.372^{* * *} \\
(0.589)\end{array}$ & $\begin{array}{l}1.005 \\
(1.845)\end{array}$ & $\begin{array}{c}1.968^{* * *} \\
(0.114)\end{array}$ \\
\hline High Education & $\begin{array}{c}2.821^{* * *} \\
(0.288)\end{array}$ & $\begin{array}{c}2.728^{* * *} \\
(0.75)\end{array}$ & $\begin{array}{c}1.922^{* * *} \\
(0.097)\end{array}$ \\
\hline Low Education & $\begin{array}{c}11.219 \\
(17.888)\end{array}$ & $\begin{array}{c}-3.997 \\
(26.034)\end{array}$ & $\begin{array}{c}2.067^{* * *} \\
(0.144)\end{array}$ \\
\hline FT employed & $\begin{array}{c}6.581 \\
(7.439)\end{array}$ & $\begin{array}{l}1.99^{* * *} \\
(0.419)\end{array}$ & $\begin{array}{c}1.796^{* * *} \\
(0.116)\end{array}$ \\
\hline no-FT & $\begin{array}{c}3.417^{* * * *} \\
(0.432)\end{array}$ & $\begin{array}{c}5.602 \\
(34.681)\end{array}$ & $\begin{array}{c}2.229^{* * * *} \\
(0.12)\end{array}$ \\
\hline Income $<75 \mathrm{~K}$ & $\begin{array}{l}5.626^{* *} \\
(2.803)\end{array}$ & $\begin{array}{l}-1.395 \\
(20.555)\end{array}$ & $\begin{array}{c}2.278^{* * *} \\
(0.134)\end{array}$ \\
\hline Income $\geq 75 \mathrm{~K}$ & $\begin{array}{c}3.028^{* * *} \\
(0.433)\end{array}$ & $\begin{array}{c}2.309^{* * *} \\
(0.62)\end{array}$ & $\begin{array}{c}1.756^{* * *} \\
(0.127)\end{array}$ \\
\hline Coop./Alt. & $\begin{array}{l}3.60^{* * *} \\
(0.543)\end{array}$ & $\begin{array}{c}2.336^{* * *} \\
(0.435)\end{array}$ & $\begin{array}{c}2.055^{* * *} \\
(0.10)\end{array}$ \\
\hline Agg./Comp./Ind./Other & $\begin{array}{l}-2.021 \\
(7.434)\end{array}$ & $\begin{array}{c}3.209^{* * *} \\
(0.90)\end{array}$ & $\begin{array}{c}1.876^{* * *} \\
(0.19)\end{array}$ \\
\hline
\end{tabular}

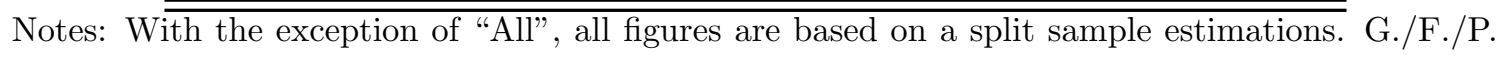
health denotes good/fair/poor self-assessed health status. E./VG. denotes excellent/very good self-assessed health status. Coop./Alt. denotes cooperative-altruistic value orientations. Agg./Comp./Ind./Other denotes aggresive, competitive, individualistic or other social value orientations. 


\section{Appendix C.}

\section{Post stratification weights}

The purpose of post-stratification weights is to correct for known differences between the experimental sample and the population. By re-weighting the data to match the Ontario age-sex distribution we remove any systematic bias in responses resulting from different response rates across these categories. Nevertheless, we note that such weights do not account for other potential sources of bias (i.e. arising from questionnaire design, data collection).

We calculate the post-stratification weights as a ratio of the Ontario population frequencies based on estimates from the Canadian Community Health Survey and cell frequencies in our survey:

Proportional weights are calculated as follows (Little 1993):

$$
w_{h}=\frac{r P_{h}}{r_{h}}
$$

Where $w_{h}$ is the post-stratification weight calculated for post-stratum $h$ (i.e. age categories, sex), $r_{h}$ is the proportion of survey respondents in post-stratum $h$, and $r P_{h}$ is the population proportion from the Canadian Community Health survey.

With our sample consisting of older participants (i.e., mean age 59 yrs. for experimental sample versus 44 yrs. for Ontario) and a disproportionate number of males (i.e. $77 \%$ or experimental sample versus $48 \%$ for Ontario) the corresponding weights in some post-strata are large. Specifically, those under 35 yrs. and particularly females under 35 yrs. have post-stratification weights several times higher than weights for other categories. The weights are given in Table C1.

Table C1: Untrimmed post-stratification weights by age and sex

\begin{tabular}{|c|c|c|}
\hline Age (yrs.) & Male & Female \\
\hline$<35$ & 10.5 & 17.8 \\
\hline $35-49$ & 1.0 & 2.3 \\
\hline $50-64$ & 0.3 & 1.2 \\
\hline $65-79$ & 0.3 & 1.6 \\
\hline$>80$ & 0.4 & 6.6 \\
\hline
\end{tabular}




\section{Trimming post-stratification weights}

Large weights lead to weighted estimates that have a high variance. By trimming the large weights, we reduce the variance however at the cost of introducing bias. Weighting, in general, increases the variance of estimates, the increase in variance can overwhelm the decrease in bias, hence weight trimming can be worthwhile. We trim post-stratification weights by reducing the large weights to a fixed (arbitrarily chosen in our case) cut-point value and adjust the weights below that cut-point value to maintain untrimmed weight sum (Elliot M.R and Little R.J.A. (2000)). Table C2 gives the resulting trimmed weights.

Table C2: Trimmed post-stratification weights by age and sex

\begin{tabular}{ccccc}
\hline \hline Age (yrs.) & & Male & & Female \\
\cline { 1 - 1 }$<35$ & & 7.0 & & 7.0 \\
$35-49$ & & 2.7 & & 6.4 \\
$50-64$ & & 1.0 & & 3.5 \\
$65-79$ & & 0.7 & & 4.5 \\
$>80$ & & 1.2 & & 7.0 \\
\hline \hline
\end{tabular}


Table C3: Mean IA values for income, health and bivariate distributions from weighted structural estimations

\begin{tabular}{|c|c|c|c|c|c|c|}
\hline \multirow[b]{3}{*}{ All } & \multicolumn{2}{|c|}{ Income distribution } & \multicolumn{2}{|c|}{ Health distribution } & \multicolumn{2}{|c|}{ Bivariate distribution } \\
\hline & $\epsilon$ & $\ln (\sigma)$ & $\epsilon$ & $\ln (\sigma)$ & $\gamma$ & $\ln (\sigma)$ \\
\hline & $\begin{array}{l}3.27^{* * *} \\
(0.519)\end{array}$ & $\begin{array}{c}-23.554^{* * *} \\
(4.945)\end{array}$ & $\begin{array}{c}1.385^{* * *} \\
(0.464)\end{array}$ & $\begin{array}{l}-3.007 \\
(2.231)\end{array}$ & $\begin{array}{c}1.614^{* * *} \\
(0.051)\end{array}$ & $\begin{array}{c}0.831^{* * *} \\
(0.089)\end{array}$ \\
\hline Age $\leq 60$ & $3.28^{* * *}$ & $-24.087^{* * *}$ & $1.186^{* * *}$ & $-3.191^{* *}$ & $1.974^{* * *}$ & $0.863^{* * *}$ \\
\hline Age $>60$ & $3.27^{* * *}$ & $-23.231^{* * *}$ & 3.326 & $\begin{array}{l}-9.213 \\
-58084)\end{array}$ & $1.489^{* * *}$ & $0.787^{* * *}$ \\
\hline Females & $\begin{array}{c}(0.704) \\
3.328^{* * *} \\
(0.569)\end{array}$ & $\begin{array}{c}(6.703) \\
-24.595^{* * *} \\
(5.425)\end{array}$ & $\begin{array}{c}(15.537) \\
1.421^{* * *} \\
(.252)\end{array}$ & $\begin{array}{c}(58.084) \\
-4.104^{* * *} \\
(1.21)\end{array}$ & $\begin{array}{c}(0.053) \\
1.798^{* * *} \\
(0.111)\end{array}$ & $\begin{array}{c}(0.101) \\
1.001^{* * *} \\
(0.159)\end{array}$ \\
\hline Males & $\begin{array}{l}3.21^{* * *} \\
(0.981)\end{array}$ & $\begin{array}{c}-22.502^{* *} \\
(9.338)\end{array}$ & - & - & $\begin{array}{c}1.512^{* * *} \\
(0.056)\end{array}$ & $\begin{array}{c}0.707^{* * *} \\
(0.105)\end{array}$ \\
\hline G./F./P. health & $\begin{array}{c}3.319^{* * *} \\
(0.808)\end{array}$ & $\begin{array}{c}-23.995^{* * *} \\
(7.696)\end{array}$ & $\begin{array}{l}1.74^{* * *} \\
(0.582)\end{array}$ & $\begin{array}{l}-4.84^{* *} \\
(2.377)\end{array}$ & $\begin{array}{c}1.607^{* * *} \\
(0.063)\end{array}$ & $\begin{array}{c}0.48^{* * *} \\
(0.116)\end{array}$ \\
\hline E./VG. health & $\begin{array}{c}3.216^{* * *} \\
(0.65)\end{array}$ & $\begin{array}{c}-23.065^{* * *} \\
(6.19)\end{array}$ & $\begin{array}{c}1.07 \\
(0.715)\end{array}$ & $\begin{array}{l}-1.632 \\
(3.694)\end{array}$ & $\begin{array}{c}1.611^{* * *} \\
(0.077)\end{array}$ & $\begin{array}{c}1.045^{* * *} \\
(0.132)\end{array}$ \\
\hline High Education & $\begin{array}{l}3.03^{* * *} \\
(0.995)\end{array}$ & $\begin{array}{c}-21.277^{* *} \\
(9.473)\end{array}$ & $\begin{array}{c}4.218 \\
(5.133)\end{array}$ & $\begin{array}{l}-14.268 \\
(19.895)\end{array}$ & $\begin{array}{c}1.577^{* * *} \\
(0.056)\end{array}$ & $\begin{array}{c}0.527^{* * *} \\
(0.102)\end{array}$ \\
\hline Low Education & $\begin{array}{c}3.319^{* * *} \\
(0.61)\end{array}$ & $\begin{array}{c}-23.976^{* * *} \\
(5.811)\end{array}$ & $\begin{array}{c}0.191 \\
(1.297)\end{array}$ & $\begin{array}{c}2.024 \\
(6.323)\end{array}$ & $\begin{array}{c}1.629^{* * *} \\
(0.092)\end{array}$ & $\begin{array}{c}1.101^{* * *} \\
(0.156)\end{array}$ \\
\hline FT employed & $\begin{array}{c}3.329^{* * *} \\
(0.94)\end{array}$ & $\begin{array}{c}-23.655^{* * *} \\
(8.95)\end{array}$ & $\begin{array}{c}1.665^{* * *} \\
(0.206)\end{array}$ & $\begin{array}{c}-5.406^{* * *} \\
(0.871)\end{array}$ & $\begin{array}{c}1.425^{* * *} \\
(0.052)\end{array}$ & $\begin{array}{c}0.748^{* * *} \\
(0.106)\end{array}$ \\
\hline no-FT & $\begin{array}{c}3.221^{* * *} \\
(0.586)\end{array}$ & $\begin{array}{c}-23.634^{* * *} \\
(5.579)\end{array}$ & - & - & $\begin{array}{c}2.013^{* * *} \\
(0.136)\end{array}$ & $\begin{array}{c}0.878^{* * *} \\
(0.154)\end{array}$ \\
\hline Income $<75 \mathrm{~K}$ & $\begin{array}{c}3.418^{* * *} \\
(0.581)\end{array}$ & $\begin{array}{c}-25.624^{* * *} \\
(5.539)\end{array}$ & $\begin{array}{c}0.000 \\
(0.008)\end{array}$ & $\begin{array}{c}2.944^{* * *} \\
(0.507)\end{array}$ & $\begin{array}{c}1.795^{* * *} \\
(0.1)\end{array}$ & $\begin{array}{c}0.679^{* * *} \\
(0.161)\end{array}$ \\
\hline Income $\geq 75 \mathrm{~K}$ & $\begin{array}{c}3.102^{* * *} \\
(0.754)\end{array}$ & $\begin{array}{c}-21.709^{* * *} \\
(7.181)\end{array}$ & $\begin{array}{l}4.211 \\
(6.24)\end{array}$ & $\begin{array}{l}-13.999 \\
(24.162)\end{array}$ & $\begin{array}{c}1.449^{* * *} \\
(0.058)\end{array}$ & $\begin{array}{c}0.862^{* * *} \\
(0.112)\end{array}$ \\
\hline Coop./Alt. & $\begin{array}{c}3.223^{* * *} \\
(0.511)\end{array}$ & $\begin{array}{c}-23.247^{* * *} \\
(4.871)\end{array}$ & $\begin{array}{l}2.801^{* *} \\
(1.255)\end{array}$ & $\begin{array}{c}-9.033^{* *} \\
(4.537)\end{array}$ & $\begin{array}{c}1.659^{* * *} \\
(0.062)\end{array}$ & $\begin{array}{c}0.793^{* * *} \\
(0.102)\end{array}$ \\
\hline Agg./Comp./Ind./Other & $\begin{array}{l}3.542^{*} \\
(2.052)\end{array}$ & $\begin{array}{c}-25.624 \\
(19.541)\end{array}$ & - & - & $\begin{array}{c}1.499^{* * *} \\
(0.095)\end{array}$ & $\begin{array}{c}0.945^{* * *} \\
(0.182)\end{array}$ \\
\hline
\end{tabular}

Notes: With the exception of "All", all figures are based on a split sample estimations. G./F./P. health denotes good/fair/poor self-assessed health status. E./VG. denotes excellent/very good self-assessed health status. Coop./Alt. denotes cooperative-altruistic value orientations. Agg./Comp./Ind./Other denotes aggresive, competitive, individualistic or other social value orientations. Missing values in the table denote that the model did not converge for that estimation sample. 